NBER WORKING PAPER SERIES

\title{
ESTIMATING HETEROGENEITY IN THE BENEFITS OF MEDICAL TREATMENT INTENSITY
}

William N. Evans

Craig L. Garthwaite

Working Paper 15309

http://www.nber.org/papers/w15309

\author{
NATIONAL BUREAU OF ECONOMIC RESEARCH \\ 1050 Massachusetts Avenue \\ Cambridge, MA 02138 \\ September 2009
}

The authors wish to thank the employees at OSHPD for their assistance with the data and Jonah Gelbach and Amitabh Chandra for a number of helpful discussions. This work on this project was supported by a grant from the National Institutes of Health, R01HD05289. The views expressed herein are those of the author(s) and do not necessarily reflect the views of the National Bureau of Economic Research.

NBER working papers are circulated for discussion and comment purposes. They have not been peerreviewed or been subject to the review by the NBER Board of Directors that accompanies official NBER publications.

(C) 2009 by William N. Evans and Craig L. Garthwaite. All rights reserved. Short sections of text, not to exceed two paragraphs, may be quoted without explicit permission provided that full credit, including (c) notice, is given to the source. 
Estimating Heterogeneity in the Benefits of Medical Treatment Intensity

William N. Evans and Craig L. Garthwaite

NBER Working Paper No. 15309

September 2009

JEL No. I10,I12,I18

\begin{abstract}
$\underline{\text { ABSTRACT }}$
Federal and state laws passed in the late 1990 increased considerably postpartum stays for newborns. Using all births in California over the 1995-2001 period, 2SLS estimates suggest that for the average newborn impacted by the law, increased treatment intensity had modest and statistically insignificant ( $\mathrm{p}$-value $>0.05$ ) impacts on readmission probabilities. Allowing the treatment effect to vary by pre-existing conditions or the pre-law propensity score of being discharged early, two objective measures of medical need, demonstrates that the law had large and statistically significant impacts for those with the greatest likelihood of a readmission. These results demonstrate heterogeneity in the returns to greater treatment intensity, and the returns to the average and marginal patient vary considerably.
\end{abstract}

\author{
William N. Evans \\ Keough-Hesburgh Professor of Economics \\ Department of Economics and Econometrics \\ 447 Flanner Hall \\ University of Notre Dame \\ Notre Dame, IN 46556 \\ and NBER \\ wevans1@nd.edu \\ Craig L. Garthwaite \\ Department of Management and Strategy \\ Kellogg School of Management \\ Northwestern University \\ 2001 Sheridan Road \\ Evanston, IL 60208 \\ c-garthwaite@kellogg.northwestern.edu
}




\section{Introduction}

It is not difficult to generate a case that the marginal product of medical care spending in the U.S. is very low. In 2006, per capita spending on health in the U.S. was $\$ 6,714,49$ percent more than the next highest-spending country (Norway), more than twice the median value for OECD countries, about twice the value of Canada and nearly 2.5 times the value of the United Kingdom. Despite this spending, in 2005 , the US ranked $25^{\text {th }}$ of 29 countries in average life expectancy and the US had the fourth highest infant mortality rate of 28 countries reporting countries. ${ }^{1}$ The Dartmouth Atlas Project ${ }^{2}$ shows that per capita Medicare reimbursements across hospital referral regions vary by a factor of three (Wennberg et al., 2008). Despite these spending differences, there is little evidence that the differences in spending lead to better quality of care (Baicker and Chandra, 2004) or better mortality outcomes (Fisher et al., 2003). Changes in insurance status, which are associated with large changes in care, also typically have little impact on mortality. Finkelstein and McKnight (2005) demonstrated that the introduction of Medicare dramatically increased health insurance coverage and health care spending of the elderly but the had no discernable impact on elderly mortality through the first 10 years of the program. Data from the RAND Health Insurance Experiment showed that a reduction in copayments increases health care use but has no detectable impact on health outcomes (Newhouse et al., 1993). ${ }^{3}$

The weak relationship between aggregate spending and health outcomes is in stark contrast to evidence showing pronounced medical benefits for use of specific medical devices, procedures, or pharmaceuticals. For example, advances in the treatment of heart attacks reduced the one-year mortality rate for these patients by 5 percentage points between 1984 and 1991 (Cutler et al., 1998). The use of anti-retroviral drugs among HIV/AIDS patients is associated with approximately a 70 percent drop in

\footnotetext{
${ }^{1}$ All data is from the OECD's frequently requested data series, http://www.irdes.fr/EcoSante/DownLoad/OECDHealthData_FrequentlyRequestedData.xls

2 http://www.dartmouthatlas.org/

${ }^{3}$ In contrast to these results, Card, Dobkin and Maestas (forthcoming) demonstrate that at age 65, insurance rates increase dramatically because of the Medicare program. For patients admitted to the hospital through the emergency room, Medicare enrollment is estimated to reduce death rates for these severely ill patients by 20 percent.
} 
mortality while the use of statin drugs to reduce cholesterol is associated with a 12 percent reduction in all cause mortality (Law, Wald and Rudnicka, 2003; Cholesterol Treatment Trialists' Collaborative, 2005). Between 1950 and 1990, treatment options for low birthweight infants expanded greatly, generating a 72 percent reduction in infant mortality rates over the same period (Cutler and Meara, 2000).

The disparity in the two sets of results outlined above may not be all that surprising. Studies relying on aggregate data suggest that for the average patient, the marginal productivity of additional care might be low, but, as the patient's condition becomes more sharply defined, results may not be so average. It should also not be surprising that there should be tremendous heterogeneity across patients in the benefits of greater medical care use. It is well known in the medical community that some people react well to certain treatment regimens while others receive little benefit. These differences even exist across broadly defined groups. For example, the cholesterol reductions generated by the use of statin drugs is similar for males and females but to date, there is no evidence that statins reduce mortality among females whiles there is consistent evidence of a mortality effect for males (Walsh and Pignone, 2004). Likewise, the U.S. Preventive Services Task Force (2009) concludes that daily low dose aspirin reduces heart attacks in men but not in women, while the same treatment reduces strokes in women but not men.

Establishing measurable correlates of treatment effect heterogeneity is vitally important in medical care. Kravitz et al. (2004) note that "[i]t should be obvious that treatment effects are not necessarily the same for everyone. What may not be so obvious is that misapplying averages can cause harm, by either giving patients treatments that do not help or denying patients treatments that would help them." This potential for harm is particularly true given recent attempts to introduce a greater degree of comparative effectiveness research to American health spending decisions. For example, the American Recovery and Reinvestment Act of 2009 [commonly referred to as the stimulus bill] included $\$ 1.1$ billion to establish the Federal Coordinating Council for Cost Effectiveness Research. President Barack Obama's proposed 2010 budget intends to build on this effort with the belief that this research can "enhance medical decision making by patients and their physicians" (Office of Management and Budget, 2009). In order for this decision making to improve medical outcomes, however, it is critical that 
researchers carefully consider the potential presence of heterogeneity in treatment effects. Without accounting for this heterogeneity, it is possible that a number of treatments may be deemed effective when they are not, or vice versa. This could lead to inefficient spending, or even worse, denying coverage for treatments to the whole population that are cost-effective for certain groups.

In addition to problems of comparative effectiveness research, heterogeneity can plague efforts to efficiently develop and implement preventative medicine strategies. A closer look at many broad-based preventative measures - which serve as the centerpiece in many proposed health care reforms — indicate that while many are cost-efficient ways to reduce disease incidence, few are cost saving. In a review of over 600 articles that have examined the cost-effectiveness of preventive care, Cohen et al., 2008 (p. 6623) concluded that “...the broad generalizations by many presidential candidates can be misleading. These statements convey the message that substantial resources can be saved through prevention. Although some prevention measures do save money, the vast majority reviewed in the health economics literature do not." The authors went on to point out that those programs targeted to higher-risk populations tended to generate more cost savings. The National Coalition on Health Care $(2007, \mathrm{p} .8)$ stressed this point when they noted that “...interventions are good investments when used selectively - targeted at those people who benefit most from them."4 The gains possible from more focused care are tremendous. The Dartmouth Atlas group estimates that roughly one third of Medicare expenditures are wasted on ineffective treatments.

Medical researchers have long discussed the potential effects of treatment heterogeneity. Kravitz et al. (2004) said, “[w]hen HTE [heterogeneity of treatment effects] is present, the modest benefit ascribed to many treatments in clinical trials can be misleading because modest average effects may reflect a mixture of substantial benefits for some, little benefit for many, and harm for a few." In recent years, a growing number of economic researchers have also begun to worry about estimating heterogeneity in treatment effects. This literature has been spawned by an attempt to identify, in the

\footnotetext{
${ }^{4}$ http://www.nchc.org/nchc report.pdf.
} 
words of Bitler et al. (2006) “what mean impacts miss." Work by Heckman et al. (1997) and Abadie et al. (2002) on job training, Bitler et al. (2003) on welfare reform, Chandra and Staiger (2007) on heart attack treatments and Basu et al. (2007) on breast cancer treatment, all demonstrated that the average treatment effect estimated by standard multivariate models mask substantial heterogeneity in treatment effects. The apex of this literature is a series of papers by Heckman and Vytlacil and coauthors (Heckman and Vytlacil, 1999, 2005; Heckman, Tobias, and Vytlacil, 2003; Heckman, Urzua and Vytlacil, 2006; Basu, Heckman, Navarro-Lozano, and Urzua, 2007) that developed an econometric technique called "local instrumental variables" designed to provide the entire distribution of marginal treatment effects.

In this paper, we use an exogenous increase in hospital care for newborns generated by legislative initiatives to examine the heterogeneity in the benefits of greater medical care use. In response to growing concerns about the declining length of hospital care following childbirth, 42 states and the federal government passed laws during the mid-to-late 1990s requiring insurance carriers to provide minimum length of postpartum stays. Previous research has documented that these laws greatly increased the average length of a postpartum hospital stay (Udom and Betley, 1998; Dato et al., 1996; Liu et al., 2004; Madlou-Kay and DeFor, 2005; Evans, Garthwaite and Wei, 2009) but there is conflicting evidence about whether these laws improved infant health (Madden et al., 2004; Meara et al., 2004; Datar and Sood, 2006; Evans, Garthwaite and Wei, 2009; Almond and Doyle. 2008). Most births are uncomplicated vaginal deliveries and while the extra time in the hospital generated by legislation may be restful for the new mother, it is not clear that the additional resources greatly improved medical outcomes in these routines cases (Evans, Garthwaite, and Wei, 2009; Almond and Doyle, 2008). In contrast, some evidence suggests that for more complicated pregnancies and deliveries, the extra day may mean a great deal for the health of the infant. Additionally, Almond et al. (2009) found that increasing treatment intensity, measured either in length of stay or by procedure, for very low birthweight babies $(>1500$ grams) decreased both readmissions and mortality. 
In addition to these more general questions about the potential heterogeneity in benefits from increased medical treatments, understanding the dynamics of maternity care is an interesting question in its own right. Pregnancy and delivery is one of the largest source of health expenditures in the United States. Approximately 23 percent of all hospital discharges are either mothers or newborns. In total, expenditures related to these procedures account for 27 percent of Medicaid charges and 15 percent of private insurance charges (Sakala and Corry, 2008). Due to these facts, it is important to fully understand the efficacy of changes in the level of care given to both newborns and their mothers.

The question of interest is whether newborns discharged early from a post-partum stay (defined as staying less than the recommended number of nights in the hospital) have improved infant health (as measured by hospital readmissions). As we outline below, single-equation estimates of the effect of longer mandatory post-partum stays are likely to be biased because those newborns most likely to be readmitted are also those most likely to have longer stays, understating the cost of an early discharge.

Initially, we estimate a two-stage least-square (2SLS) for all births using the legislation-induced increase in postpartum stays as an exogenous decline in the fraction of children discharged early. At first glance, this appears to be the ideal statistical environment for a 2SLS procedure. The laws reduce early discharges by about 25 percentage points and our analysis sample has over two million observations. However, the local average treatment effects (LATE) suggest a small and marginally statistically significant impact of early discharges on readmission rates. The benefits are however not uniform across newborns

Next, we estimate how the benefits of longer hospital stays vary with the observed characteristics of the newborn. In this initial analysis we use data on reported labor and delivery complications to estimate heterogeneity in the benefits of longer hospital stays. We find that individuals with any of these complications benefited from the increased length of stay, while those with uncomplicated deliveries received essentially no benefit. Unfortunately, the incidence rate for particular complications are in some cases very low making power an issue in isolating who benefits from greater treatment. 
As a second way to systematically measure treatment heterogeneity, we use a procedure suggested by both Baicker et al. (2006) and Chandra and Staiger (2007) and expanded on in detail here. Using pre-law data on mother's demographic characteristics, baby's birthweight, delivery complications, and other observable medical conditions, we estimate the propensity score for a baby being released "early" from the hospital. We next use these estimates to predict the propensity score in the post-federal law period. Given the large sample sizes and the detailed characteristics of the mother, pregnancy and delivery, the propensity score of an early discharge spans the entire $[0,1]$ interval. The distribution of the propensity score in the pre and post law period is also nearly identical. More importantly, the propensity score of an early discharge provides substantial evidence of the medical risk of a readmission. The propensity score is monotonically increasing in birth weight and gestation; and monotonically declining in the average number of complications. The readmission rate declines nearly monotonically with the propensity score suggesting that from a medical standpoint, those most likely to have a longer stay have the greatest risk of a readmission. This evidence suggests that the propensity score can be thought of as an index of the medical appropriateness of a longer length of stay in the hospital. ${ }^{5}$

We then estimate the basic 2SLS model for halves and thirds of the propensity score. These results show that those newborns with the lowest probability of being released early—often those with a large number of observable conditions and/or complications - received the largest benefit from the increased length of stay. The vast majority of individuals, however, received no benefit from the increased length of stay generated by the law.

Our results are instructive. Identifying and understanding the source of heterogeneity in the benefits of medical treatments is essential for developing effective health policy. Rather than relying on the estimated marginal benefit for the average patient, effective and targeted health policy should focus on the benefit to patients for whom the treatment or intervention is most appropriate. Failing to consider this heterogeneity in benefits could lead to erroneous conclusions about the efficacy of different policy

\footnotetext{
${ }^{5}$ This is similar to the index of the medical appropriateness of caesarian sections developed and discussed in detail in Baicker et al., (2006).
} 
initiatives. In our concrete example, the estimates suggest that the same medical benefits of early discharge laws can be achieved by applying the law only to those most in need of care rather than applying the legislation to all births.

\section{Minimum Postpartum Stay Legislation and Previous Literature}

Beginning in the 1970s and continuing until the mid-1990s, managed care cost cutting efforts and attempts to 'de-medicalize' the childbirth process lead to dramatic reduction in postpartum hospital stays for mothers and newborns (Braveman et al., 1995; Eaton, 2001). The average length of postpartum stay for vaginal births fell from 3.9 days in 1970 to 1.8 days in 1996. Over the same time period, the length of stay for caesarian section births fell from 7.8 to 3.5 days. By 1995, one day post-partum stays accounted for 47 percent of all vaginal deliveries compared to just 7.6 percent in 1980 (Hyman, 1999).

This change in the provision of medical services eventually drew popular press attention with numerous articles using the phrases "drive through" and "drive by" deliveries to describe these early discharges. News stories and articles in the medical literature began to detail tragic stories of preventable conditions afflicting mothers and newborns that were swiftly discharged from the hospital following the delivery. State lawmakers responded to these concerns with a series of laws designed to increase the length of post-partum hospital stays. Between 1995 and 1997, 43 states mandated some length of minimum postpartum stay (Eaton, 2001). California, the state of interest in this paper, passed their minimum postpartum law on August 11, 1997 and the law went into effect the same day.

Despite nearly every state passing such mandates, the preemption clause of the Employment Retirement Income Security Act (ERISA) left a large number of women (primarily those covered by multi-state and self-funded employer-provided insurance plans) unaffected by these state level mandates. As a result, in a bipartisan effort epitomized by a $98-0$ in the United States Senate, federal lawmakers passed the Newborns and Mothers Health Protection Act of 1996. This law, which went in to effect on January 1, 1998, required a minimum length of stay of 48 hours following a vaginal delivery and 96 hours 
following a caesarian section. Discharges for a stay of shorter duration required the consent of both the doctor and the patient.

While the federal law increased the number of women covered by these mandates, it still did not apply to all women. The federal statute and most state laws exempted Medicaid patients in fee-forservice plans. In California, patients in private Medicaid managed care plans were covered by both the California and federal minimum stay laws. ${ }^{6}$ Following the implementation of the federal and state statutes, lawmakers in California moved to end the unequal treatment of Medicaid patients. On August 26, 1998 the legislature passed AB 1397, which extended the California minimum postpartum stay law to all Medicaid recipients regardless of enrollment status. The effective day for this law was January 1, 1999.

As a result of these changes, new mothers in California were subject to four different legislative environments. Prior to August of 1997, there were no restrictions on what insurance companies were required to reimburse for postpartum hospital stays. Between August 1997 and the end of that year, women with private insurance and Medicaid patients in private managed care plans were subject to the state law, which was superseded by the federal statute on January 1, 1998 and expanded to cover insurance plans regulated by ERISA. Finally, the state law was expanded to include all Medicaid patients on January 1, 1999.

It is clear that these laws achieved their goal of increasing the average length of postpartum stays. Udom and Betley (1998), Dato et al. (1996), Liu et al. (2004), and Madlou-Kay and DeFor (2005) all found that the passage of the laws lengthened stays and increased medical spending. The effect of these laws on health outcomes, however, has been less clear. Madden et al. (2002 and 2004) found little impact of different length of stays on patients in Massachusetts. Using data for 150,000 newborns in Ohio, Meara et al. (2004) focused on the effect of the Ohio mandated postpartum stay law on Medicaid patients — which were explicitly covered by the state level mandate. They found that the law generated a

\footnotetext{
${ }^{6}$ Evans, Garthwaite and Wei (2008) contains a detailed discussion of the structure of the California Medicaid system and its relation to early discharge laws.
} 
statistically significant decrease in the number of early discharges and large but statistically insignificant decreases in the number of readmissions. ${ }^{7}$

Both Datar and Sood (2006) and Evans, Garthwaite and Wei (2008) used data on the universe of hospital births in California from 1995-2000 to analyze the effect of mandated increases in postpartum stays on infant health. Datar and Sood (2006) found large and statistically significant decreases in the probability of readmission for infants as a result of the mandates. Evans, Garthwaite and Wei. (2008), however, found that this finding was largely a result of data limitations in the publicly available data. Specifically, the authors are unable to control for month-to-month variation in readmission rates. Using the richer restricted-use dataset on the sample constructed in Datar and Sood (2006) finds smaller and statistically insignificant results. This sample, however, does not include a large number of complicated deliveries such as low-birthweight and premature infants. Including all births, Evans, Garthwaite and Wei (2009) found that for privately insured c-section patients and for Medicaid-insured vaginal deliveries the longer hospital stays generated small but statistically significant decreases in 28 day readmissions.

Almond and Doyle (2009) used the exact timing of birth as the basis of a regression discontinuity identification strategy to estimate the effect of longer postpartum stays on infant health in California. The authors exploit a billing rule which causes babies born just after midnight to receive another day of reimbursable care compared to those born just before midnight. Furthermore, the authors utilized the fact that the California mandate further increased the length of stay for these infants born just after midnight (in this case from 2 days of care for those just before midnight to three days of care for those after midnight). Using this strategy, the authors find no effect of longer hospital stays on infant health for uncomplicated deliveries.

Despite the large number of studies, there is little consensus of the effect of laws mandating longer hospital stays on infant health. Most studies in this area eliminate at least some categories of

\footnotetext{
${ }^{7}$ The authors, however, did find that a follow-up visit within three days caused a statistically significant decrease in the probability of a hospital readmission within 10 days of birth. Importantly for the purposes of this analysis, the authors focused on "normal" newborns - eliminating those below 2000 grams and with a gestational age of less than 37 weeks, or without the diagnosis related group (DRG) code for "normal newborn." It is possible that the largest impact of Ohio's mandate may have been for these more complicated cases.
} 
complicated births under the assumption that these mothers and newborns would likely be unaffected by the mandated stay laws. This assumption rests on the belief that these individuals were not discharged early either before or after the law. In reality, however, a non-trivial portion of these observably complicated cases are released early. For example, from January 1, 1995 - December 31, 1996 nearly 41 percent of infants below 2500 grams in California were discharged early. After passage of the federal mandate, this rate dropped to 27 percent. Failing to consider the effect of the law on complicated cases may the source of conflicting estimates of the efficacy of longer lengths of postpartum stay.

\section{Data}

The data for this project is a restricted-use administrative record database of all mothers and newborns discharged from non-federal hospitals in California from January 1, 1995 to December 31, 2000. The data set is created by the State of California Office of Statewide Health Planning and Development (OSHPD) by linking patient discharge data sets with birth, death and fetal death certificate information. The data base contains the original discharge record for new mother and her newborn plus all other hospital discharges over the next year for these patients. Each discharge record contains basic demographic information (such as the age, race, and sex of the patient), information about the admission (such as the length of stay, procedures used, diagnoses codes, hospital charges, the type of insurance, and whether the patient died in the hospital), plus a unique hospital ID. A scrambled Social Security Number (SSN) available on the discharge record and coding by OSHPD allows records of the mother to be linked to that of her newborn.

Linking the discharge record to vital statistics files provides the exact date and time of birth (and therefore the newborn's admission to the hospital), and the zip code of residence. The birth record of the child also contains detailed information about the mother's pregnancy (an estimate of gestation, a list of complications during pregnancy, previous births, whether multiple births are present), some additional information about the mother (such as years of education) plus detailed information about the birth (such as birth weight and whether the baby was delivery by c-section, the sex of the infant and whether there 
were any delivery complications). The infant death record allows us to examine when and where a newborn died for up to one year after discharge. Our six year data base has data approximately 3 million births in total, with almost 1.7 million births occurring after the passage of the California law.

Although the early discharge laws apply to the postpartum stays for both mothers and their newborns, in this analysis we focus exclusively on the outcomes of infants. The typical outcome in this instance is a subsequent readmission rate and the rates for mothers are so low that there is little power to analyze this outcome. Therefore, the question we address is whether greater treatment intensity generated by the federal and state laws improved the health of newborns, as measured by readmission rates.

Treatment intensity is defined by the dummy variable Discharged Early which equals 1 if the newborn was released before the recommended time which is 2 days for a vaginal delivery and 4 days for a csection. $^{8}$ The health of the newborn is measured by the variable 28-Day which is an indicator that equals 1 if the newborn was readmitted to the hospital within 28 days. ${ }^{9}$

Many studies examining the effect of mandated maternity stay laws exclude large categories of newborns with complications under the justification that these individuals were likely unaffected by the mandates (Datar and Sood, 2006; Meara et al., 2004 ). Examining the pre-law means of Discharged Early, however, reveals that a non-trivial percentage of newborns with a wide variety of complications, low birth weights, and short gestation periods are discharged early from the hospital. Furthermore, as the results below will show many of these complicated births received significant benefits from the increased length of stay. In constructing the sample for this analysis, we attempted to include more complicated deliveries while excluding categories of individuals whose length of stay was essentially unaffected by the laws passage.

\footnotetext{
${ }^{8}$ Although the state and federal postpartum discharge law specifies the required time in hours, we do not have the exact hour of discharge and therefore, we cannot calculate the hours in the hospital. Therefore, we approximate the intent of the law by basing this key covariate on the number of nights in the hospital.

${ }^{9}$ We can also measure neonatal mortality and infant mortality but the incidence rates for these outcomes are low, making power a challenge even for high risk groups (Evans, Garthwaite and Wei, 2008).
} 
In the pre-law data, the percentage of individuals released early is monotonically increasing in birthweight. For this analysis, we include individuals whose birthweight was 68 ounces (4.25 pounds) or greater - the first birthweight with an early discharge rate greater than 10 percent in the pre-law period. We also exclude individuals reporting a birthweight of greater than 180 ounces (11.25 pounds) —a category accounting for only 0.1 percent of the dataset.

While newborns from multiple births are often excluded from these analyses, a large fraction of both twins (60\%) and triplets (40\%) are discharged early in the pre-law period. Therefore, we include and control for individuals in these categories while excluding quadruplets or higher-individuals who were rarely discharged early in the pre-law period.

In the data, gestation is measured in days and is calculated by taking the difference between the last normal menses and the date of birth. For a variety of reasons, this results in gestational age being a very noisy measure in the dataset. Therefore, we exclude individuals whose reported gestation was less than 182 days (26 weeks) or greater than 315 days (45 weeks).

The linked Hospital Discharge Data/Vital Statistics birth files contain a wealth of information on complications and concurrent illnesses affecting either the mother or the infant. These data comes from the Certificate of Live Birth - Medical Data Supplemental Worksheet. This worksheet contains 30 possible complications or concurrent illnesses affecting pregnancy (medical providers can select up to 16) and 31 possible complications affecting the labor and delivery (medical providers can select up to 9). We generate indicator variables for the presence of conditions or complications that may affect the length of stay for a mother or infant. In doing so we created composite category for pre-eclampsia, eclampsia, and herpes - which were included in the both the pregnancy and the delivery complications section of the worksheet. We also exclude those data that are related to medical procedures, such as electronic fetal monitoring or ultrasound, as opposed to underlying medical conditions. This results in a total of 45 dummy variables that indicate complications. ${ }^{10}$

\footnotetext{
${ }^{10}$ The complications dummies are defined for the following conditions: 1. Preeclampsia (pregnancy induced hypertension); 2. Eclampsia (convulsion or coma); 3. Hypertension, chronic; 4. Renal disease; 5. Pyelonephritis; 6.
} 
In the top two rows of Table 1, we report the sample means for two periods. The first is in the period before any early discharge law was in effect in California, which is January 1995 through August of 1997. The second period is after the federal law goes into effect which provides coverage to all privately insured births and Medicaid managed care births that are part of private plans. This period covers January 1998 through the end of 2000. There are 1.18 million births in the first sample and 1.32 million births in the other. In the first two rows, we present results for the two key outcomes in the analysis: Discharged Early and 28-Day readmission. Notice that there is a large drop in early discharges of 27 percentage points yet there is only two tenths of a percentage point change in readmission rates, suggesting that at best, the law had modest impact, on average readmission rates.

In the remaining rows of the table, we present means of some important characteristics of the mother and the delivery. There is no change in average birth weights between the two periods and a slight decrease in the fraction of births with any of the 45 problems identified in the birth record data set. Across the two periods, there is 10 percent increase in the number c-section deliveries and a 13 percent decline in the fraction of births paid for by Medicaid. There is a slight decline in mothers without a high school education, a noticeable drop in births to Black mothers, a slight decline in births to younger women and a slight increase in the fraction of births to Hispanic mothers. Given the extremely large sample sizes, all differences in the two columns except for the gestation variable are statistically significant.

Anemia; 7. Cardiac disease; 8. Lung disease, acute or chronic; 9. Diabetes; 10. Rh sensitivity; 11. Uterine bleeding before labor; 12. Hemoglobinopathy; 13. Transport of mother from another facility prior to delivery; 14. Polyhydramnios; 15. Incompetent cervix; 16. Premature labor; 17. Genital herpes; 18. Other STD; 19. Hepatitis B; 20. Rubella; 21. Smoking; 22. Birth weight $>4000$ grams; 23; Birth weight $<2500$ grams; 24. Cervical cerclage; 25 . $<37$ weeks gestation; 26. Chronic villus sampling; 27. Cord prolapse; 28. Fetal distress; 29. Seizures during delivery; 30. Maternal blood transfusion; 31. Fetopelvic disproportion; 32. Shoulder dysotcia; 33. Breech presentation; 34 . Precipitous delivery ( $<3$ hours); 35. Prolonged delivery ( $>20$ hours); 36 . Unsuccessful attempt at vaginal birth after c-section; 37 . Other dysfunctional delivery; 38. Premature rupture of membrane ( $>12$ hoours); 39. Abruptio placenta; 40. Placentia previa; 41. Other excessive bleeding; 42. Amnionitis/sepsis; 43. Febrile ( $\left.>100^{\circ} \mathrm{F}\right)$; 44. Presence of meconium, moderate/heavy; 45. Anesthetic complications. 


\section{Empirical Model and Baseline Results}

In theory, we could estimate the impact of an early discharge on the 28-day readmission rate via a single-equation OLS model where we control for a detailed set of covariates describing the mother, the pregnancy, and the delivery. Let $\mathrm{y}_{\mathrm{it}}$ represent readmission rates for person $\mathrm{i}$ in time period $\mathrm{t}$. The equation of interest related how an early discharge $\left(\mathrm{x}_{\mathrm{it}}\right)$ alters readmission rates and this can be captured by the equation

(1) $y_{i t}=\beta_{0}+x_{i t} \beta_{1}+w_{i t} \beta_{2}+\varepsilon_{i t}$

where $\mathrm{w}_{\mathrm{it}}$ represents a vector of exogenous covariates and $\varepsilon_{\mathrm{it}}$ is a random error. In practice, however, this model is likely to be subject to an omitted variables bias and we anticipate that $\operatorname{cov}\left(\mathrm{x}_{\mathrm{it}}, \varepsilon_{\mathrm{it}}\right)<0$. Evans, Garthwaite and Wei (2008) demonstrate that factors which tend to increase the probability of 28-Day are also tending to reduce Discharged Early. For example, Discharged Early rates are lowest for first births, multiple births, younger women, women with insurance, and those with complications such as low birth weight, breech presentation, preeclampsia or eclampsia. These same characteristics are also those factors that predict greater readmission rates among newborns. This suggests that $\operatorname{cov}\left(\mathrm{x}_{\mathrm{it}}, \varepsilon_{\mathrm{it}}\right)<0$ and single equation estimates of $\beta_{1}$ will be biased towards zero.

OLS estimates of equation (1) using only data from the pre-law period (January 1995 through August 1997) are provided at the top of Table 2. In this equation, we control for a number of covariates including dummies for all 45 prenatal and delivery complications, a complete set of dummies that describe the age, education, race, marital status, twins, triplets, and Hispanic origin of the mother, a dummy for the sex of the newborn, dummies that measure the month, year, weekday of birth, and birth hour, plus dummies that measure the ownership of the hospital, the size of the hospital and the hospital service region within California. Because readmission rates vary considerably based in type of delivery (vaginal or c-section) and insurance status (private or Medicaid) we include a set of dummies for privately insured c-sections, Medicaid insured vaginal deliveries, Medicaid insured c-sections with privately insured vaginal births as the reference group. We also include cubic terms in birthweight and gestational 
age. Finally, we include a liner trend in the months since January 1995 plus three trends that vary based insurance status/delivery method dummies outlined above. In all, there are 163 covariates in this model and 1,176,797 observations. In this and subsequent models, we estimate the variance/covariance matrix allowing for arbitrary correlation in errors within a particular hospital.

In this instance, the estimated of the impact of an early discharge on readmission rates is rather modest. The coefficient in the first line of Table 2 suggests that an early discharge raises the probability of a readmission by a statistically insignificant tenth of a percentage point which is approximately 3 percent of the sample mean.

Given a vector of instruments $z_{\mathrm{it}}$ that predict early discharge rates but are uncorrelated with unexplained portion of equation (1) we can use 2SLS to provide a consistent estimate of $\beta_{1}$. In this case, the federal and state early discharge laws provide useful variation that can be exploited as instruments. As we demonstrate below, the laws decreased dramatically the fraction of newborns discharged early. If the greater intensity of care improves newborn health, we should see a noticeable drop in readmission rates after passage of the various state and federal laws.

A graphical treatment of the first stage and reduced form models associated with the 2SLS estimation are presented in Figures 1 and 2 respectively. In Figure 1, we present the monthly averages for the percent discharge early from January 1995 through the end of 2001 . On the graph, we indicate the periods when the state law was only in effect (which only covered some private and Medicaid patients), when the federal law went into effect (which covered all privately insured births and Medicaid patients in privately provided Medicaid managed care plans) and when the state law was expanded to include all Medicaid patients. Note first that early discharges were declining slowly prior to the passage of the state law but early discharge rates did not drop sharply until the state law was passed and went into effect the same day. Insurance carriers did not appear to be adjusting to the federal law in advance of its effective date. Second, the change in early discharge rates produced by the various statutes is very large. In July of 1997, early discharge rates were 77 percent. By January of 1998, this number had fallen to 57 percent and by January of 1999, the rate was down to 52 percent. 
In Figure 2, we graph the time series of the 28-day readmission rates for the same period. The dotted lines represent the mean readmission rates during the pre-law, state law, federal law and expanded state law period, respectively. Three results are apparent in these graphs. First, the month to month variation in readmission rates is incredibly large with readmission rates highest during the winter months. Second, during the 4 months the state law was in effect, there was a large spike in readmissions, generated by a particularly heavy flu season. As a result, any analysis of the benefits of greater intensity of care will generate spurious results showing more care produces worse outcomes during this period since the intensity of care increased (early discharge rates fell) and readmission soared. For this reason, in our subsequent regression work, we will delete data from the four month period when the state law was only in effect. Third, there is a small but noticeable drop in readmission rates when the federal law and expanded state law go into effect. Between the pre-law and federal law period, readmission rates fell by about 2 tenths of a percentage point and rates fell by another 1 tenth of a percentage point in the expanded state law period.

We present a set of 2SLS results estimates in the bottom of Table 2. In this case, we estimate a model similar to the OLS model but include data from January 1995 through December of 2001, excluding the four months the state law was the only law in effect (September - December 1997). We include the same set of covariates as in the OLS model. As instruments for Discharged Early, we exploit the timing of the laws and the fact that the laws impacted patients based on their insurance status and method of delivery. We use six instruments in total. We allow the federal law to vary based on insurance status (private versus Medicaid) and delivery method (vaginal and c-section) and we allow the expansion of the state law to all Medicaid patients to effect vaginal and c-section deliveries for this group as well.

In the middle of the table, we present the first stage estimates for the instruments in the Discharged Early equation. All of the instruments are statistically significant and suggest that the various early discharge laws worked as anticipated albeit with differing levels of success. For those with private insurance, the federal law reduced early discharges by 30 percentage points among vaginal births but by only 13.7 percentage points among c-sections. Among Medicaid patients, the federal law again had its 
largest impact on vaginal deliveries. The expansion of the state law to include Medicaid patients reduced early discharges by another 5 to 6 percentage points for both vaginal and c-section deliveries. The F-test that the instruments are jointly zero indicates that this hypothesis can be easily rejected and the size of the test statistic indicates that there is no concern associated with finite sample bias.

In the final portion of Table 2 we report the 2SLS estimates of the readmission equation. As expected, the 2SLS estimate on Discharged Early is larger than the OLS values. The estimated coefficient of 0.005 is statistically significant at the 10 percent level and represents a change of about 15 percent of the sample mean for the 28-Day Readmission in the pre-law period. Even with the extreme size of our sample and the precise first-stage estimates for all instruments, the p-value on the test of overidentifying restrictions is greater than 0.05 meaning we cannot reject the null the model is properly specified.

\section{Heterogeneity in the Returns to Greater Medical Care Use}

2SLS results are often interpreted as a local average treatment effect (LATE) as outlined by Angrist, Imbens and Rubin (1996). Within the LATE framework, the 2SLS model identifies the impact of the endogenous variable of interest for those people whose behavior was altered as a result of receiving the instrument. In this context, the 2SLS model identifies the impact of staying longer in the hospital for the 25 percent of newborns who had longer stays as a result of the various federal and state early discharge laws. The sample means in Table 1, the graphical treatment in Figure 2, and now the 2SLS estimates in Table 2 all tell a similar story - the benefits of longer stays for the average newborn impacted by the law are modest at best. This result is consistent with the 'flat of the curve' story that is typically used to describe medical care in the US. Given third party reimbursements, the marginal cost to insured consumers of using additional medical care is low. As a result, medical care will be consumed to the point where marginal benefits equal marginal cost. Hence, the marginal benefits of additional treatments are low. 
Not all newborns are however subject to the same risk of readmission and as a result, one would not expect the benefits of longer hospital stays to be the same across different groups. The early discharge laws were a rather blunt policy instrument - all newborns, regardless of risk, were eligible for a minimum stay of two days after a vaginal birth and four days after a c-section, regardless of the underlying risk. From a policy standpoint if one could a priori identify those at the greatest risk of readmission and apply the law only to those newborns, the law might be able to generate similar medical outcomes at a much lower cost.

From an econometric standpoint, identifying heterogeneity in the returns to longer stays across different groups is hampered by two factors. First, the incidence rate for the outcome of interest (readmission with 28 days) is low so identifying precise 2SLS estimates is a challenge even with our large sample sizes. From Table 2, note that with over 2 million observations, a first stage that changes treatment use by 25 percentage points, and a treatment effect that is 15 percent of the sample mean, the results are only statistically significant at a p-value of 0.10 . While we can generate large sub-samples of people with easily identifiable characteristics (e.g., those born by c-section, Medicaid patients), we anticipate that even within these large relatively heterogeneous groups the treatment effect will likely vary. Second, we anticipate that longer hospital stays should be most beneficial to those most in medical need. However, those with higher risks of readmission are already staying longer in the hospital, meaning that the first stage relationship should be smaller for this group. Since the precision of the second stage model is related to the size of the first stage effect, the declining first-stage for those most in need of treatment should lessen our ability to detect a precise 2SLS estimate in the groups most likely to benefit. In this analysis, we attempt to isolate heterogeneity in the returns to additional medical care use through two procedures. Initially, we restrict the sample to groups with easily identifiable demographic and medical characteristics and examine the treatment heterogeneity across those subsamples. This method produces some predictable results. For example, in each case, the 2SLS coefficient is greater than the OLS estimate suggesting that the OLS models systematically understate the benefits of longer stays. However, there are few statistically significant 2SLS coefficients and it is hard to identify persistent 
patterns across the subgroups. Given these results, we then suggest a procedure based on the propensity score of early discharge to aggregate the data about the risks of readmission to newborns.

\section{a. Heterogeneity in Results by Specific Characteristics}

In Table 3, we report 2SLS estimates for certain subgroups of newborns. In the first row of the table we reproduce 2SLS estimates for the full sample from Table 2. For each model, we report the observations, the pre-law sample means for Discharged Early and 28-day, the OLS and 2SLS estimates on the Discharged Early variable, the p-value on the test of over identifying restrictions and the first-stage f-statistic for the test of the null that that all instruments have a zero coefficient. In the next two rows, we provide estimates for subgroups based on type of delivery (C-sections and vaginal deliveries). The 2SLS estimates on Discharged Early in the vaginal delivery sample is small and statistically insignificant. In contrast, the coefficient on the same variable in the C-section models is a statistically significant 1.9 percentage points - nearly 70 percent of the sample mean.

Next, we exploit the detailed data available on the birth records and hospital discharge record to consider the impact of longer stays for newborns with certain sets of risk factors. As we noted above, our data allows us to construct 45 dummy variables that measure complications associated with the pregnancy or delivery. In an initial probit equation using data from the pre-law period, we modeled the probability of an early discharge as a function of the list of covariates used in Table 2 which includes these 45 conditions. We then identified those problems that were estimated to have a statistically significant decrease in the probability of an early discharge. These conditions can be thought of as those characteristics that a priori were considered by providers and the newborn's parents as requiring additional treatment and therefore, these can be considered as indicators of enhanced medical risk or need for additional care. For lack of a better term, we call these "severe problems" and we estimate 2SLS models of sample of newborns with $0,1+, 2+$ and $3+$ severe problems. These results are reported in the final four rows of Table 3 . 
Note that as we move from 0 to $3+$ problems, sample size shrinks considerably, the early discharge rate in the pre-law period falls precipitously, and likewise, the readmission rate increases nearly monotonically. The 2SLS coefficient on the Discharged Early variable in the "no problems" sample is the smallest estimate in that column with a statistically insignificant value of 0.0024 , a number that is only 7 percent of the sample mean. In contrast, the same coefficient in the $1+$ sample is a statistically significant 1.6 percentage points (approximately 40 percent of the sample mean) and the coefficient doubles to 3.2 percentage points (approximately 75 percent of the sample mean) in the $2+$ problems sample with a p-value of 0.07 . In the $3+$ problem sample, the estimated 2 SLS coefficient is even larger at 5 percentage points but the drop in the sample size to 27,102 observations results in a statistically insignificant result.

We have three additional general comments about the results in Table 3. First, in all cases, the 2SLS estimates of the Discharged Early coefficient are larger than the OLS estimates, suggesting that the OLS results are biased downwards. This is no surprise: those with the greatest risk of a readmission have longer hospital stays so the coefficient on Discharged Early will be biased down. Second, in all cases the first-stage f-statistic testing the null that the coefficients on the instruments are all zero is large dispelling any concern about finite sample bias in the 2SLS models. Third, on average, the first-stage f-statistic is positively related with the pre-law Discharged Early rates (correlation coefficient is 0.68). Again, this is no surprise - only those who would otherwise be discharged early can be impacted by the law, so the law should have a smaller impact on those who are already staying longer.

In order to better understand the underlying conditions driving the compelling pattern of results in Table 3, we select 5 of the largest prenatal/delivery problems and estimate separate models for newborns who present with these specific conditions. In Table 4 we present the results based on the incidence rate of the condition, from largest to smallest. Three of the five 2SLS estimates on the Discharged Early variables are statistically significant (in the fetal distress, diabetes, and preeclampsia/eclampsia samples). These point estimates are large in magnitude ranging from 3.5 percentage points ( 83 percent of the sample mean) for the diabetes sample to nearly 5.5 percentage points ( 135 percent of the sample mean) 
for the preeclampsia/eclampsia sample. In the other two other cases (the meconium delivery and other dysfunctional delivery samples), the estimated LATE is fairly large - 45 to 60 percent of the sample mean—but these results are not statistically significant.

The inconsistent pattern of results by condition status displays a need for a more systematic method of identifying the pattern of heterogeneity in the benefit of longer hospital stays. One natural candidate for this systematic method is birthweight. A baby's birthweight has been a focal point of researchers for establishing increased medical need. The last two rows of Table 4 contain the results for sample based on a baby being above or below $5 \mathrm{lbs}$. While neither 2SLS estimate is statistically significant, they suggest an underlying pattern of heterogeneity. The estimated effect for babies with a birthweight less than $5 \mathrm{lbs}$ is 10 times larger than the point estimate for those weighing more than $5 \mathrm{lbs}$. Individuals weighing less than 5 lbs clearly have high medical need, as seen by the Discharged Early rate of only 28.8 percent and a 28 day readmission rate of 4.2 percent. In contrast, approximately 80 percent

of individuals above 5 lbs have are discharged early from the hospital and they have a 28 day readmission rate of 3.4 percent. The difficulty is that low birthweight individuals are exceptionally low in number (fewer than 40,000 babies in the dataset are smaller than $5 \mathrm{lbs}$ at birth) making it difficult to produce statistically significant estimates.

Overall, the results in Tables 3 and 4 suggest several factors that may be useful in identifying heterogeneity in the treatment effect. First, our measure of problems provides an indicator of medical need that is reflected in lower early discharges and higher readmission rates in the pre-law period. Second, as these medical problems accumulate, the benefits of avoiding an early discharge increase considerably. Third, for the vast majority of patients in the sample, there is no estimated medical benefit to longer hospital stays.

\section{b. Using the Propensity Score to Identify Medical Need}

As discussed above, identifying a pattern in the results using either individual conditions or birthweight is hampered by the relatively small sample sizes and the need for a systematic method for 
grouping people based on their relative levels of medical need. In order to overcome this problem, we utilize the rich medical and demographic data on individuals during the pre-law period to identify patients who are most likely, in the opinion of medical practitioners, to require longer hospital stays. Specifically, we estimate the following probit equation on a sample of individuals during the time period before the federal or state mandate:

$$
\text { Prob(Discharged Early } \left.\mathrm{it}_{\mathrm{it}}=1\right)=\mathrm{P}_{\mathrm{it}}=\Phi\left[\gamma_{0}+\mathrm{W}_{\mathrm{it}} \gamma_{2}\right]
$$

where $\Phi$ is the standard normal CDF and all other variables are defined as in equation (1). The predicted probability from this equation is the propensity score, and it provides valuable information about the clinical opinion of the appropriateness of additional medical care. Higher levels of this propensity score indicate individuals who are more likely to be discharged early from the hospital. Conversely, lower values are individuals whose medical conditions required longer hospital stays. We estimate the parameters from this model with pre-law data only because the decisions are based on medical parameters before the physician's and patient's decision was altered by legislation. As the numbers in Figure 1 indicate, there is little if any trend in the dependent variable from January of 1995 through August of 1997 so it does not appear that the underlying factors used to decide whether to discharge a newborn early were altered much over that period.

In Figure 3, we present a histogram of the distribution of the propensity score in the pre-law and post federal law period. The vertical axis is the propensity score rounded to the nearest 0.01 and the lines represent the fraction of the sample with a propensity score with that value. The dark lines on the left hand side represent the pre-law period and the light grey lines represent the post federal law period. Within the graph, two results are of note. First, given the large number of observations and the number of detailed covariates in the model, it should be no surprise that the propensity score of an early discharge spans all values from 0.00 to 1.00 . Second, the pre and post-law periods have virtually identical 
distributions. Therefore, aggregating data within ranges of the propensity score and comparing outcomes pre and post law, we are comparing similar populations in size and distribution of propensity scores.

The informational content of the propensity score about medical need appears to be quite high as well. We break the pre and post law propensity scores into 20 even-sized groups (vigintiles) and graph the mean value of newborn birth weight (Figure 4), the mean value of gestation in days (Figure 5) and number of complications (Figure 6) against the vigintiles of the propensity score. In Figures of 4-6, two trends are evident. First, the propensity score does an excellent job of reflecting risk to the newborn. Moving from the lowest to highest vigintile in the propensity score, the average birth weight and gestational age increases and the mean number of complications decline. In both of these graphs the relationships are monotonic and the curves for the pre and post-law period lie virtually on top of each other suggesting that the propensity score in both periods is providing similar information about these two groups.

For similarly defined people, we anticipate that the early discharge laws have very different effects in the post law period on discharges and readmissions. In Figure 7, we graph the early discharge rates for the pre and post periods against the vigintiles of the propensity score. Again, there appears to be tremendous information about the underlying health of the newborn. For both periods, early discharge rates are nearly monotonically increasing in the vigintiles of the propensity score. We should expect large gaps between the post and pre-law graphs because the laws decrease the probability of an early discharge for similarly defined people. However, the gap is not uniform within the sample. Between the $5^{\text {th }}$ and the $15^{\text {th }}$ vigintiles, the average change in early discharge rates is nearly 34 percentage points. In contrast, the average for individuals between the $1^{\text {st }}-5^{\text {th }}$ and the $15^{\text {th }}-20^{\text {th }}$ vigintiles is only 22 percentage points. This shows that early discharge laws have less of an impact on the length of stay for newborns who are always discharged early (high propensity scores) or those we anticipate are in most need of more intensive treatment (low propensity scores).

Finally, in Figure 8, we graph the 28 day readmission rate for both groups against the vigintiles of the propensity score. The information content of the propensity score about the underlying health of the 
infant is illustrated by the fact that for both groups, readmission rates are nearly monotonically declining as we increase the propensity score. The gap between the two curves is somewhat uniform across the vigintiles of the propensity score but we should note that this graph in some respects represents a reduced form relationship — what is the impact of the early discharge laws on similarly defined people? Recall from Figure 6 that for people in the middle vigintiles of propensity scores the change in early discharge rates was much greater than at the tails so the implied local average treatment suggested by the two graphs will be very different than the reduced form model suggested by the reduced form graph.

Table 5 contains the 2SLS estimates for groupings of individuals based on their respective propensity scores. For each model, we present the same estimates as in Table 3 and 4 . Choosing the appropriate group size for each model involves balancing the risk of Type II errors caused by small sample sizes with the risk of watering down the estimated treatment effect by including too many individuals who may differ in the likely benefit generated from a longer hospital stay. As can be seen in Figure 3 , while the propensity score is identified across the $(0,1)$ support, the vast majority of observations have high propensity scores. Therefore, the number of individuals with low scores - those who are most likely to stay longer in the hospital—is relatively small.

Given these tradeoffs, we estimate the 2SLS models by breaking the sample into halves and thirds of the predicted Discharged Early propensity score and estimate the 2SLS model outlined in equation (1) for each of these subgroups. Examining the results in the bottom two thirds of Table 5 reveals several consistent trends. First, as was graphically seen in Figure 5, the readmission rate is monotonically declining in the propensity score. Second, as with previous tables, the 2SLS estimates are always larger than the OLS estimates, again providing suggestive evidence that the OLS model is biased down because those with the greatest risk of a readmission are the least likely to be discharged early. Finally, the F-tests for the null hypothesis that first stage instruments are all zero are all uniformly large.

In the first two rows of the table, we report results by halves of the propensity score. Readmission rates for newborns in the bottom half of the propensity score are 15 percent higher than for those in the upper half, suggesting greater medical need for treatment in the lower half. The 2SLS 
estimate of the Discharged Early variable in the bottom half of the propensity score is over twice the size of the estimate from the top half. The estimated effect for those in the bottom half of the propensity score distribution is 0.7 percentage points (20 percent of the sample mean) and is statistically significant at the 10 percent level. In contrast, the estimated effect for those in the top half of the distribution is only 0.3 percentage points and has a standard error that is the same size as the point estimate. For those in the bottom half, the 2SLS estimate at the mean suggests that being discharged early increases the chance of a readmission by almost a half a percentage point which is nearly 20 percent of the sample mean.

When we break the propensity score up into thirds, the bottom third of the distribution has a prelaw period readmission rate that is 30 percent higher than the rate for those in the top third. Classifying individuals into thirds based on their propensity score shows large differences in the estimated mean effect of being discharged early. Individuals in the bottom third of the propensity score distribution who are discharged early have an estimated increase the chance of a readmission of 1.1 percentage pointswhich is 28 percent of the sample mean. This estimate is statistically significant at the 5 percent level and dwarfs that estimate for those in the middle third of the distribution. For these newborns, at the mean, being discharge early increases the chance of a readmission by one tenth of a percentage point which is only 3 percent of the sample mean. The standard error for this estimate is three times the parameter value, however. To compare the magnitudes, the estimated effect for those in the lowest third of the distribution is 10 times larger than those in the middle of the distribution.

\section{Conclusion}

The state and federal early discharge laws were passed in part because health care providers felt the pendulum towards more expedient care had swung too far and patients were at risk of subsequent complications because they were being discharged too early. As other papers have documented and the results in this paper further illustrate, the early discharged laws have achieved an intermediate goal of increasing the length of post partum stays: early discharges fell by 27 percentage points which is one third of the pre-law sample mean. However, the ultimate goal of the laws was to improve patient health and on 
this score, there is a mixed set of results. On average, being discharged early is estimated to have a small and marginally statistically significant impact on readmission rates. However, this small estimate masks considerable heterogeneity in the benefits of the more intensive treatment. For those in the lower third or quarter of the probability of being discharged early, a group with a priori the greatest medical need for care, the law is estimated to reduce the chance of a readmission by almost 30 percent. In contrast, there is little if any evidence of a benefit to greater treatment intensity for those with less medical need. The narrow conclusion is that the same laws can generate the same health care outcomes with substantially reduced costs by focusing the attention of the law on those most in need of additional care.

The broader conclusion is that more care must be taken when estimating the efficacy of medical intervention. The above results highlight the need to consider heterogeneity in expected benefits when estimate the efficacy of new treatments or policies. Dramatic increases in health expenditures have caused health systems around the globe to consider the efficacy of medications before including them in their coverage. For example, the National Institute for Health and Clinical Excellence (NICE) in the United Kingdom was established in 1999 to provide guidance to the National Health Service about which treatments are cost effective and should be covered. Furthermore, as the United States begins another effort to reform its complex and expensive health care system there appears to be greater attention to the cost-effectiveness of medical treatments. In determining the efficacy of various treatments and policies it is important to carefully consider potential heterogeneity in the expected benefits. This can allow for more effective and targeted policies that can achieve the same or better health outcomes at a reduced cost. 


\section{References}

Abadie, Alberto, Joshua Angrist, and Guido Imbens, "Instrumental Variable Estimates of the Effect of Subsidized Training on the Quantils of Trainee Earnings," Econometrica 70:1 (2002), 91-117.

Almond, Douglas, and Joseph J. Doyle, "After Midnight: A Regression Discontinuity Design in Length of Postpartum Hospital Stays,” NBER working paper no. 13877 (March 2008).

Almond, Douglas, Joseph J. Doyle, Jr., Amanda E. Kowalski, and Heidi Williams, "Estimating Marginal Returns to Medical Care: Evidence from At-Risk Newborns," NBER working paper no. 14522 (December 2008), forthcoming in Quarterly Journal of Economics.

Angrist, Joshua D., Guido W. Imbens, and Donald B. Rubin, "Identification of Causal Effects Using Instrumental Variables," Journal of the American Statistical Association 91:434 (1996), 444-455.

Baicker, Katherine, and Amitabh Chandra, "Medicare Spending, the Physician Workforce and Beneficiaries' Quality of Care," Health Affairs Web Exclusive (2004), 184-197.

Baicker, Katherine, Kasey S. Buckles, and Amitabh Chandra, "Geographic Variation in Appropriate Use of Cesarean Section," Health Affairs Web Exclusive (2006), w355-367.

Basu, Anirban, James J. Heckman, Salvador Navarro-Lozano, and Sergio Urzua, "Use of Instrumental Variables in the Presence of Heterogeneity and Self-Selection: An Application to Treatments of Breast Cancer Patients," Health Economics 16:11 (2007), 1133-1157.

Bitler, Marianne P., Jonah B. Gelbach, and Hilary W. Hoynes, "What Mean Impacts Miss: Distributional Effects of Welfare Reform Experiments,” American Economic Review 96:4 (2006), 989-1012.

Braveman, Paula, Susan Egerter, Michelle Pearl, Kristen Marchi, and Carol Miller, "Early Discharge of Newborns and Mothers: A Critical Review of Literature,” Pediatrics 96:4 (1995), 716-726.

Card, David, Carlos Dobkin and Nicole Maestas, “Does Medicare Save Lives?” Quarterly Journal of Economics (forthcoming).

Chandra, Amitabh, and Douglas O. Staiger, "Productivity Spillovers in Health Care: Evidence from the Treatment of Heart Attacks," Journal of Political Economy 115:1 (2007), 103-140.

Cholesterol Treatment Trialists' Collaborative, "Efficacy and Safety of Cholesterol-Lowering Treatment: Prospective Meta-Analysis of Data from 90,056 Participants in 14 Randomized Trials of Statins," The Lancet 366:9493 (2005), 1267-1278.

Cohen, Joshua T., Peter J. Neumann, and Milton C. Weinstein, "Does Preventive Care Save Money? Health Economics and the Presidential Candidates," New England Journal of Medicine 358:7 (2008), 661-663.

Cutler, David M., Mark McClellan, Joseph P. Newhouse, and Dahlia Remler, “Are Medical Prices Declining? Evidence from Heart Attack Treatments," Quarterly Journal of Economics 113:4 (1998), 9911024.

Cutler , David M., and Ellen Meara, “The Technology of Birth: Is It Worth It?" Forum for Health Economics \& Policy (Frontiers in Health Policy Research) 3:3 (2000), 1-35. 
Datar, Ashlesha, and Neeraj Sood, "Impact of Postpartum Hospital-Stay Legislation on Newborn Length of Stay, Readmission, and Mortality in California," Pediatrics 118:1 (2006), 63-72.

Dato, V., L. Ziskin, M. Fulcomer, R.M. Martin, and K. Knoblauch, “Average Postpartum Length of Stay for Uncomplicated Deliveries - New Jersey, 1995," Morbidity \& Mortality Weekly Report 45:32 (1996), 700-704.

Duggan, Mark G., and William N. Evans, "Estimating the Impact of Medical Innovation: A Case Study of HIV Antiretroviral Treatments," Forum for Health Economics \& Policy (Economics of the HIV Epidemic) 11:2 (2008), 1-37.

Eaton, Antoinette Parisi, "Early Postpartum Discharge: Recommendations from a Preliminary Report to Congress," Pediatrics 107:2 (2001), 400-403.

Evans, William N., Craig Garthwaite, and Heng Wei, "The Impact of Early Discharge Laws on the Health of Newborns," Journal of Health Economics 27:4 (2008), 843-870.

Finkelstein, Amy, and Robin McKnight, "What Did Medicare Do (And Was It Worth It)?” NBER working paper no. 11609 (September 2005).

Fisher, Elliott S., David E. Wennberg, Therese A. Stukel, Daniel J. Gottlieb, F.L. Lucas, and Etoile L. Pinder, "The Implications of Regional Variation in Medicare Spending. Part 2: Health Outcomes and Satisfaction with Care," Annals of Internal Medicine 138:4 (2003), 288-298.

Heckman, James J., Jeffrey Smith, Nancy Clements, "Making the Most Out of Programme Evaluations and Social Experiments: Accounting for Heterogeneity in Programme Impacts," Review of Economic Studies 64:4 (1997), 487-535.

Heckman, James J., Justin L. Tobias, and Edward J. Vytlacil, "Simple Estimators for Treatment Parameters in a Latent Variable Framework," Review of Economics and Statistics 85:3 (2003), 748-755.

Heckman, James J., and Edward J. Vytlacil, "Local Instrumental Variables and Latent Variable Models for Identifying and Bounding Treatment Effects," Proceedings of the National Academy of Sciences 96:8 (1999), 4730-4734.

Heckman, James J., and Edward J. Vytlacil, "Structural Equations, Treatment Effects, and Econometric Policy Evaluation," Econometrica 73:3 (2005), 669-738.

Heckman, James J., Sergio Urzua, and Edward J. Vytlacil, "Understanding Instrumental Variables in Models with Essential Heterogeneity," Review of Economics and Statistics 88:3 (2006), 389-432.

Hyman, David A., "Drive-Through Deliveries: Is Consumer Protection Just What the Doctor Ordered?" North Carolina Law Review 78:1 (1999), 5-100.

Kravitz, Richard, Naihua Duan, and Joel Braslow, "Evidence-based medicine, heterogeneity of treatment effects, and the trouble with averages," Milbank Quarterly 82 (2004), 661-687,

Law, Malcolm R., Nicholas L. Wald, and A.R. Rudnicka, "Quantifying Effect of Statins on Low Density Lipoprotein Cholesterol, Ischemic Heart Disease, and Stroke: Systematic Review and Meta-Analysis," British Medical Journal 326:7404 (2003), 1423-1429. 
Liu, Zhimei, William H. Dow, and Edward C. Norton, "Effect of Drive-Through Delivery Laws on Postpartum Length of Stay and Hospital Charges," Journal of Health Economics 23:1 (2004), 129-155.

Madden, Jeanne M., Stephen B. Soumerai, Tracy A. Lieu, Kenneth D. Mandl, Fang Zhang, and Dennis Ross-Degnan, "Effect of a Law Against Early Postpartum Discharge on Newborn Follow-Up, Adverse Events, and HMO Expenditures," New England Journal of Medicine 347:25 (2002), 2031-2038.

Madden, Jeanne M., Stephen B. Soumerai, Tracy A. Lieu, Kenneth D. Mandl, Fang Zhang, and Dennis Ross-Degnan, "Length-of-Stay Policies and Ascertainment of Postdischarge Problems in Newborns," Pediatrics 113:1 (2004), 42-49.

Madlon-Kay, Diane J., and Terese A. DeFor, "Maternal Postpartum Health Care Utilization and the Effect of Minnesota Early Discharge Legislation," Journal of the American Board of Family Practice 18:4 (2005), 307-311.

Meara, Ellen, Uma R. Kotagal, Harry D. Atherton, and Tracy A. Lieu, "Impact of Early Newborn Discharge Legislation and Early Follow-up Visits on Infant Outcomes in a State Medicaid Population," Pediatrics 113:6 (2004), 1619-1627.

Newhouse, Joseph P., and the Insurance Experiment Group, Free For All? Lessons from the RAND Health Insurance Experiment (Cambridge, MA: Harvard University Press, 1996).

Office of Management and Budget, “A New Era of Responsibility: Renewing America’s Promise,” 2009.

Sakala, Carol and Maureen Corry, "Evidence Based Maternity Care: What It Is and What It Can Achieve," Milbank Memorial Fund, 2008.

Udom, Nduka, and Charles L. Betley, "Effects of Maternity-Stay Legislation On 'Drive-Through Deliveries," Health Affairs 17:5 (1998), 208-215.

U.S. Preventive Services Task Force, "Aspirin for the Prevention of Cardiovascular Disease: U.S. Preventive Services Task Force Recommendation Statement," Annals of Internal Medicine 150:6 (2009), 396-404.

Walsh, Judith M.E., and Michael Pignone, "Drug Treatment of Hyperlipidemia in Women," Journal of the American Medical Association 291:18 (2004), 2243-2252.

Wennberg, John E., Elliott S. Fisher, David C. Goodman and Jonathan S. Skinner, Tracking the Care of Patients with Severe Chronic Illness - The Dartmouth Atlas of Health Care 2008 (Lebanon, NH: Dartmouth Institute for Health Policy and Clinical Practice, Center for Health Policy Research, 2008). 
Figure 1: Percent of Newborns in California Discharged Early, Privately Insured and Medicaid Births, 1995-2000

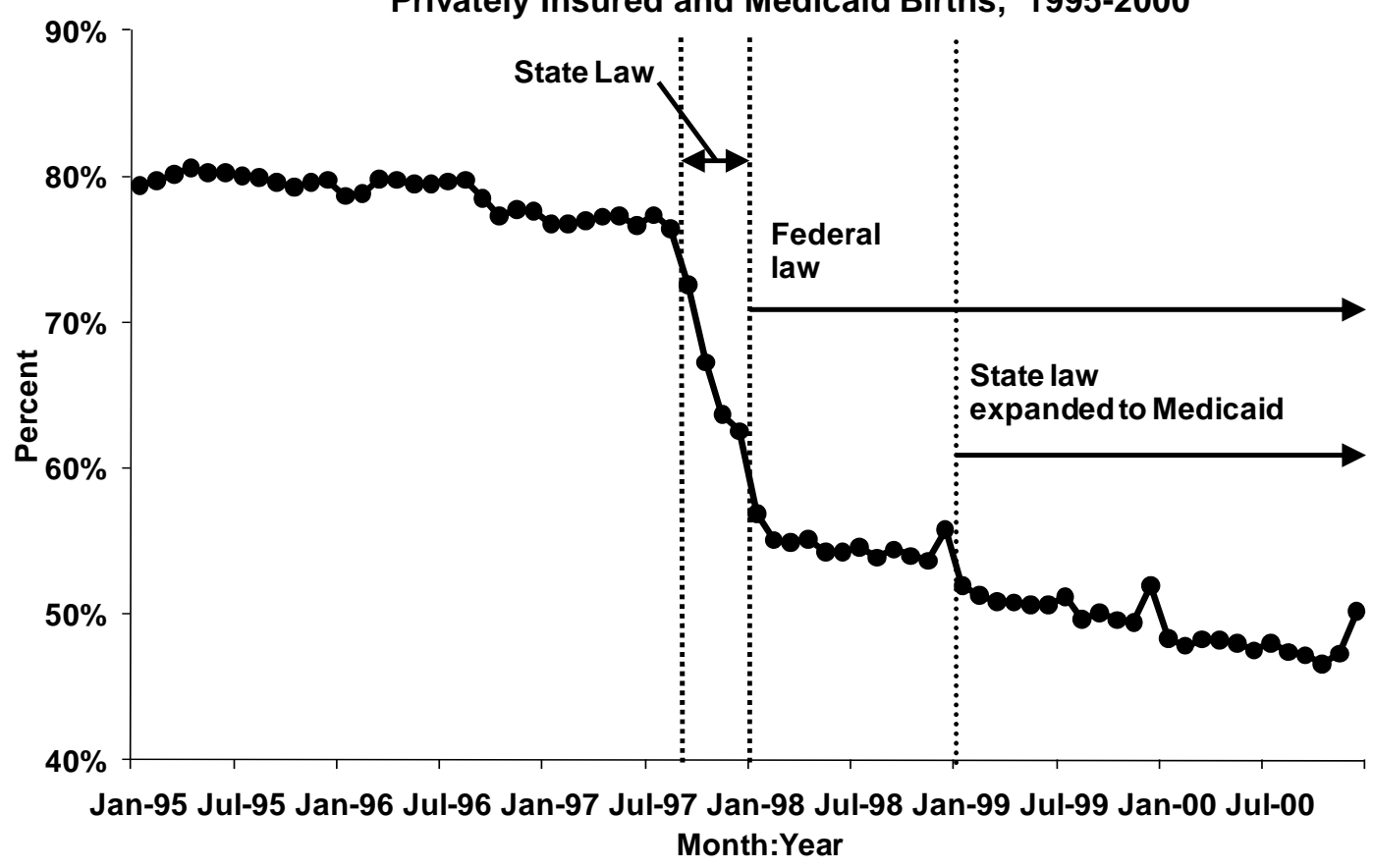

Figure 2: Percent of Newborns in California with a 28-Day Readmission, Privately Insured and Medicaid Births, 1995-2000

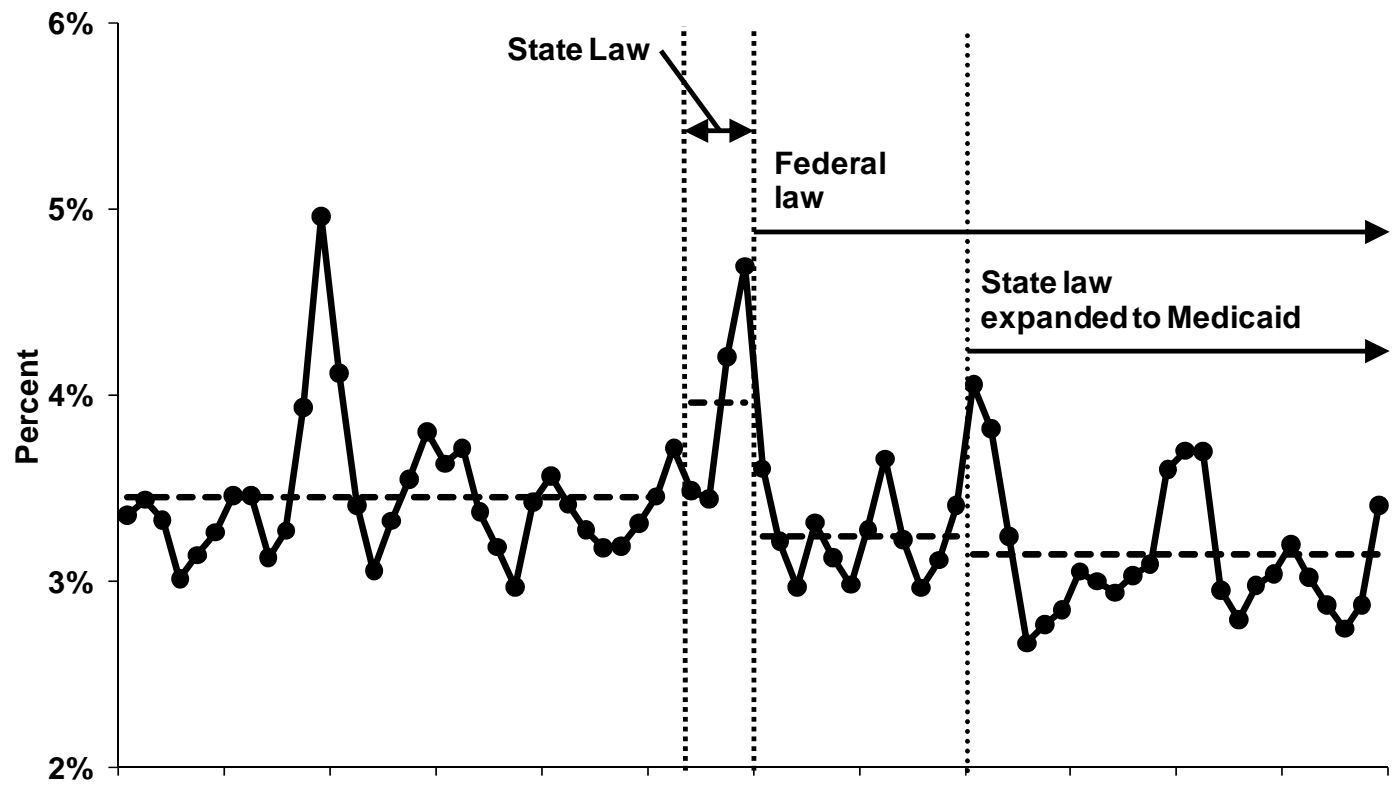

Jan-95 Jul-95 Jan-96 Jul-96 Jan-97 Jul-97 Jan-98 Jul-98 Jan-99 Jul-99 Jan-00 Jul-00 Month:Year 
Figure 3: Histogram of Distribution of Propensity Scores, Privately Insured and Medicaid Births, 1995-2000

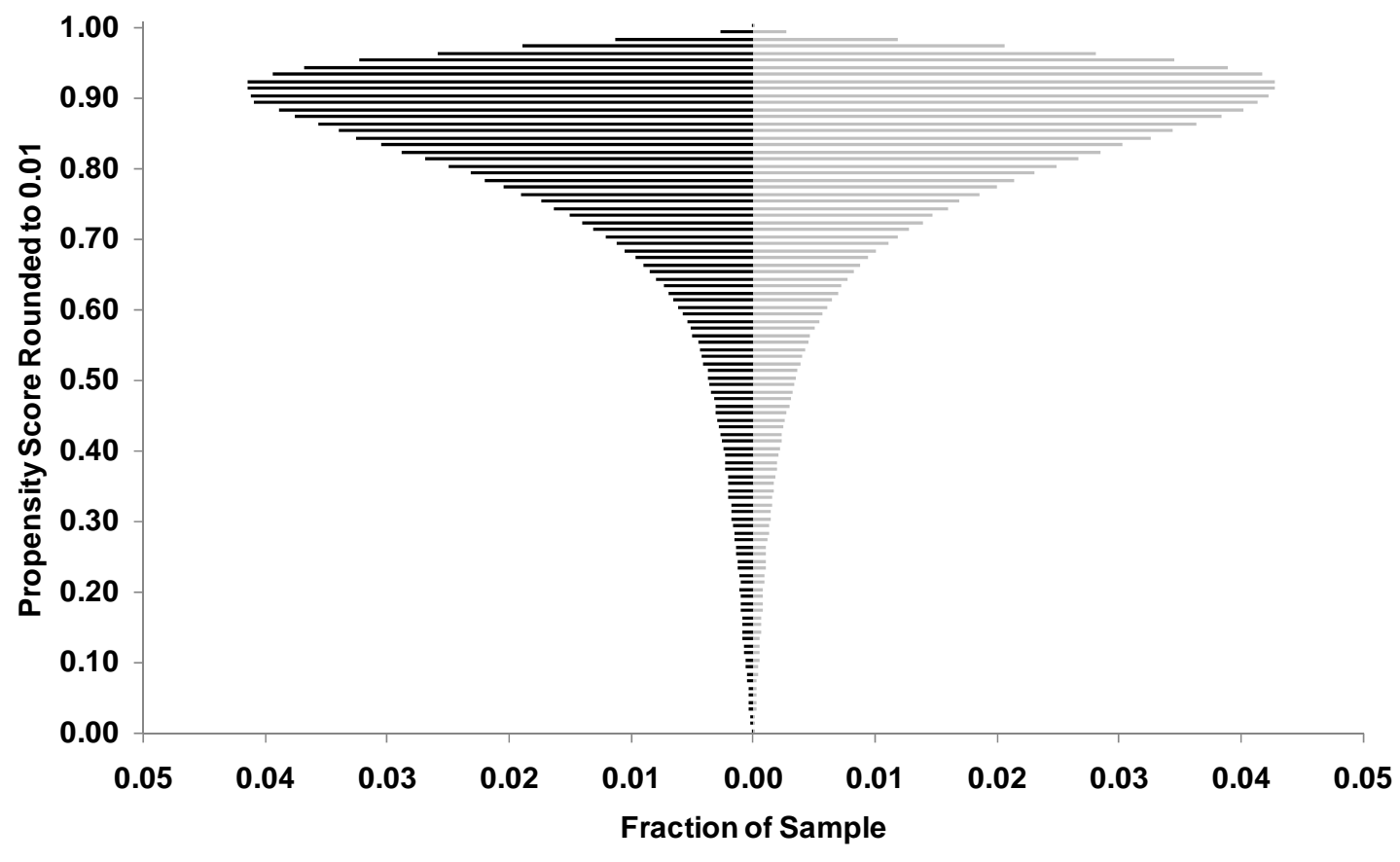

- Pre Law Post Law

Figure 4: Mean Birth Weight in Ounces by Vinitiles of the Propensity Score, Privately Insured and Medicaid Births in California, 1995-2000

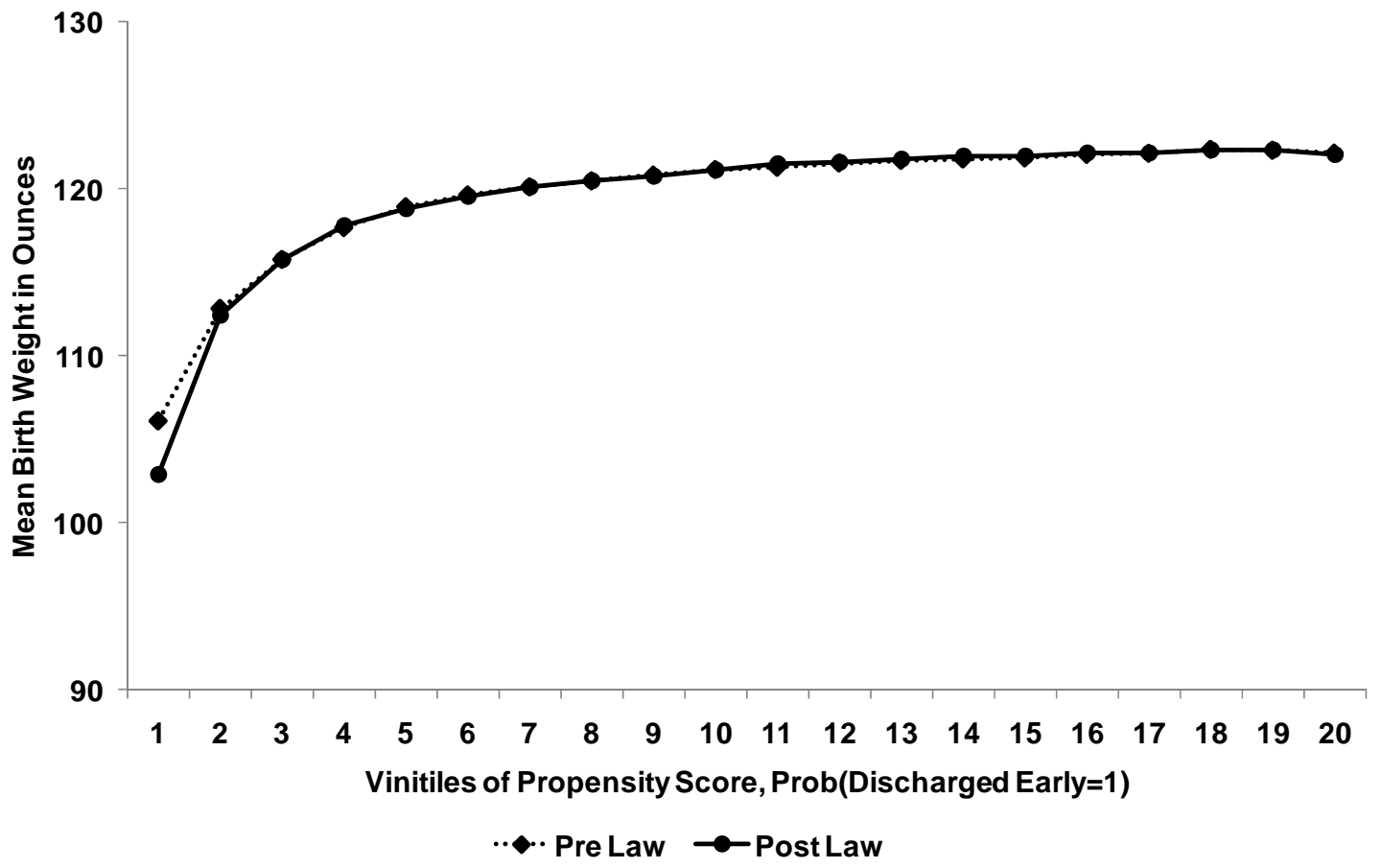


Figure 5: Mean Days Gestation by Vinitiles of the Propensity Score, Privately Insured and Medicaid Births in California, 1995-2000

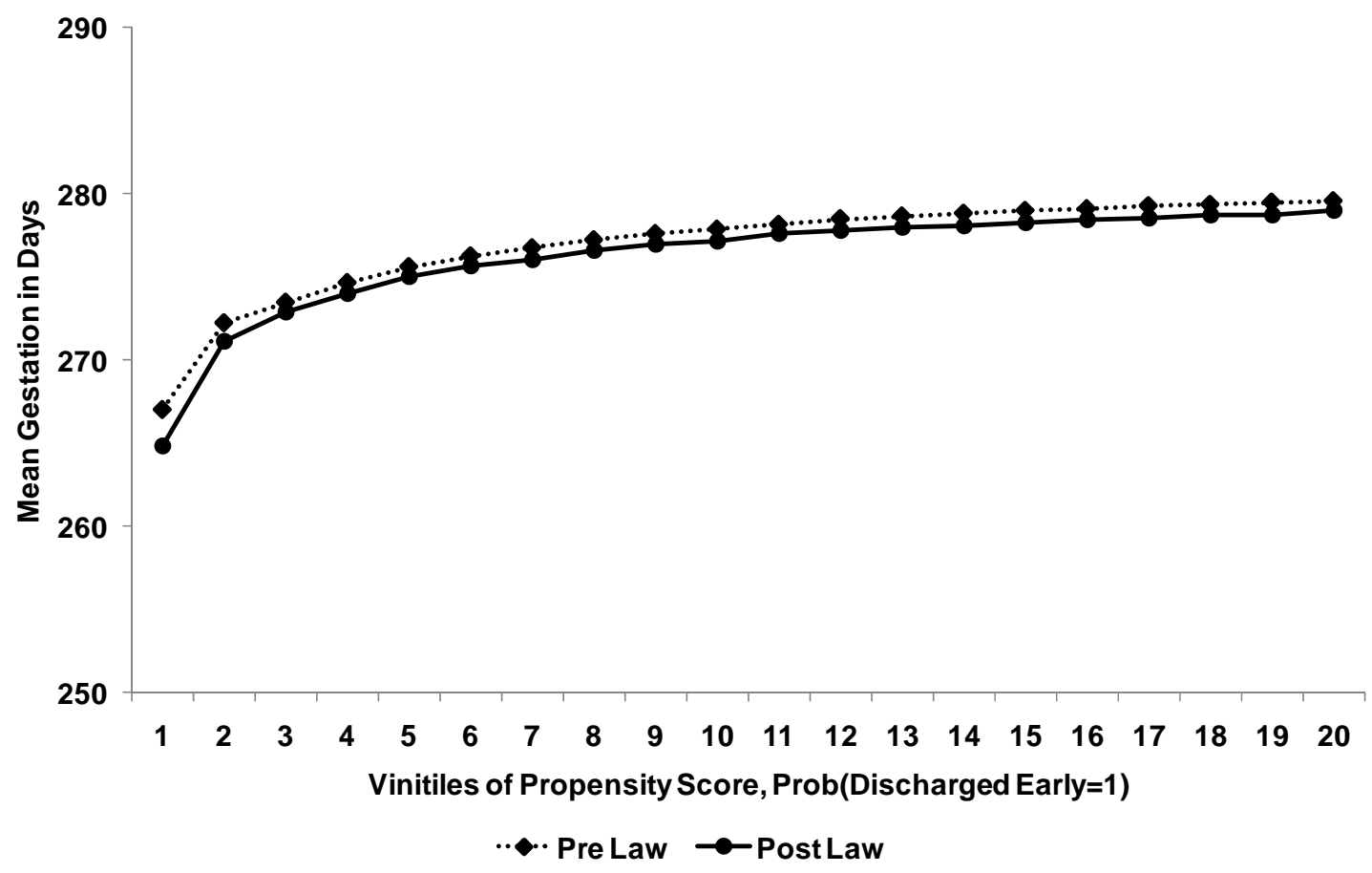

Figure 6: Mean Complications by Vinitiles of the Propensity Score, Privately Insured and Medicaid Births in California, 1995-2000

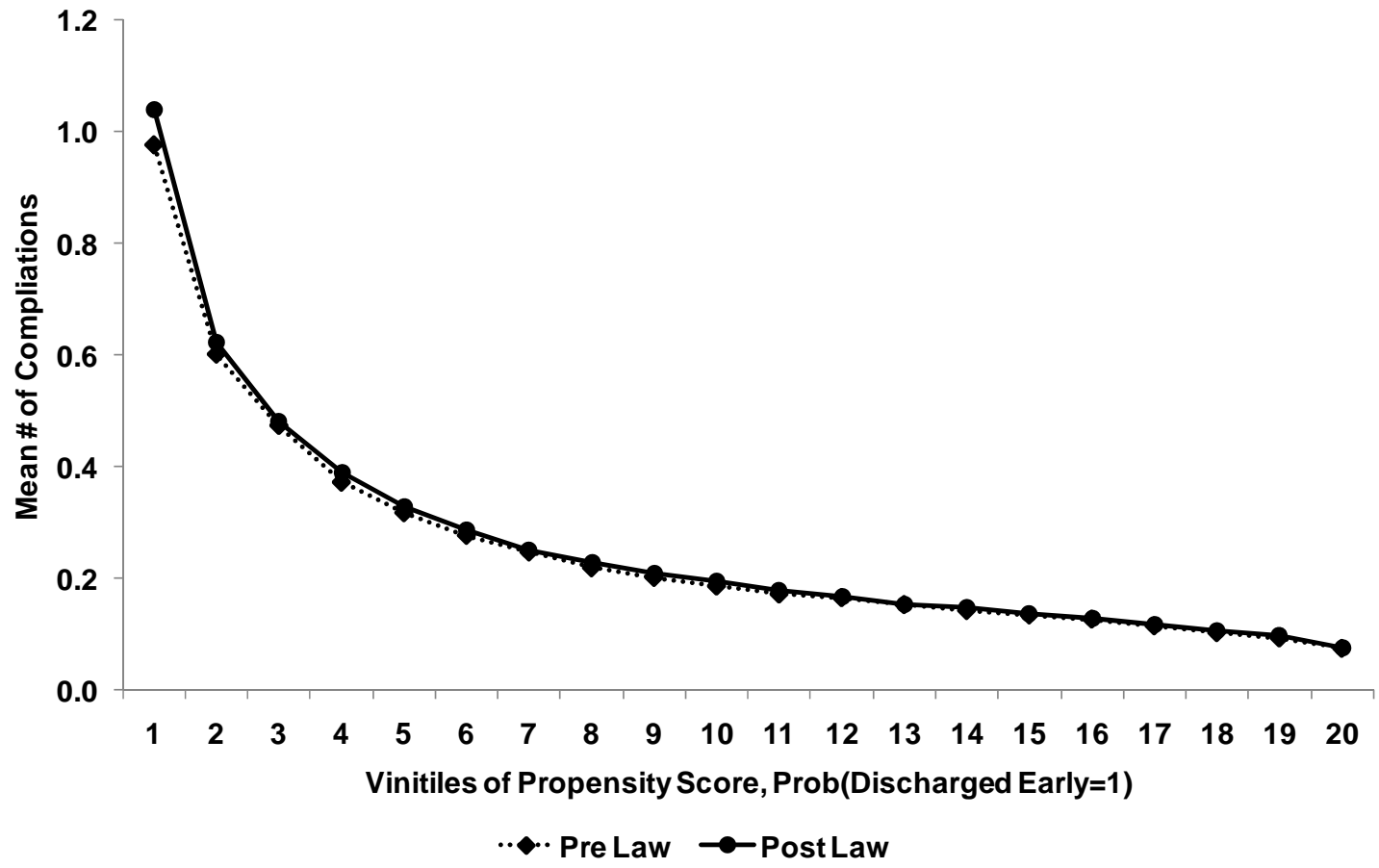


Figure 7: Percent Discharged Early by Vinitiles of the Propensity Score, Privately Insured and Medicaid Births in

California, 1995-2000

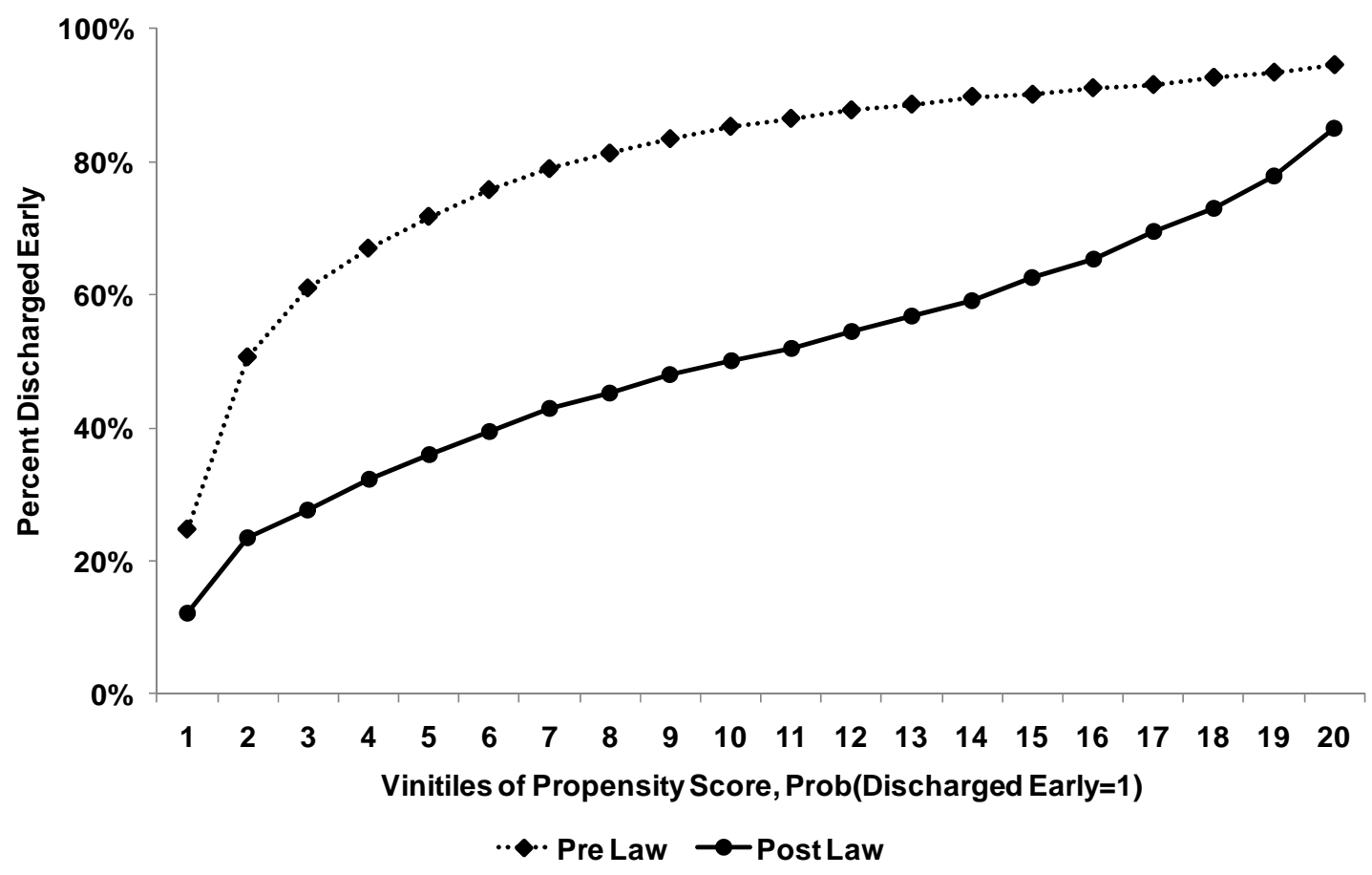

Figure 8: Percent Readmitted w/in 28 Days by Vinitiles of the Propensity Score, Privately Insured and Medicaid Births, Caliifornia 1995-2000

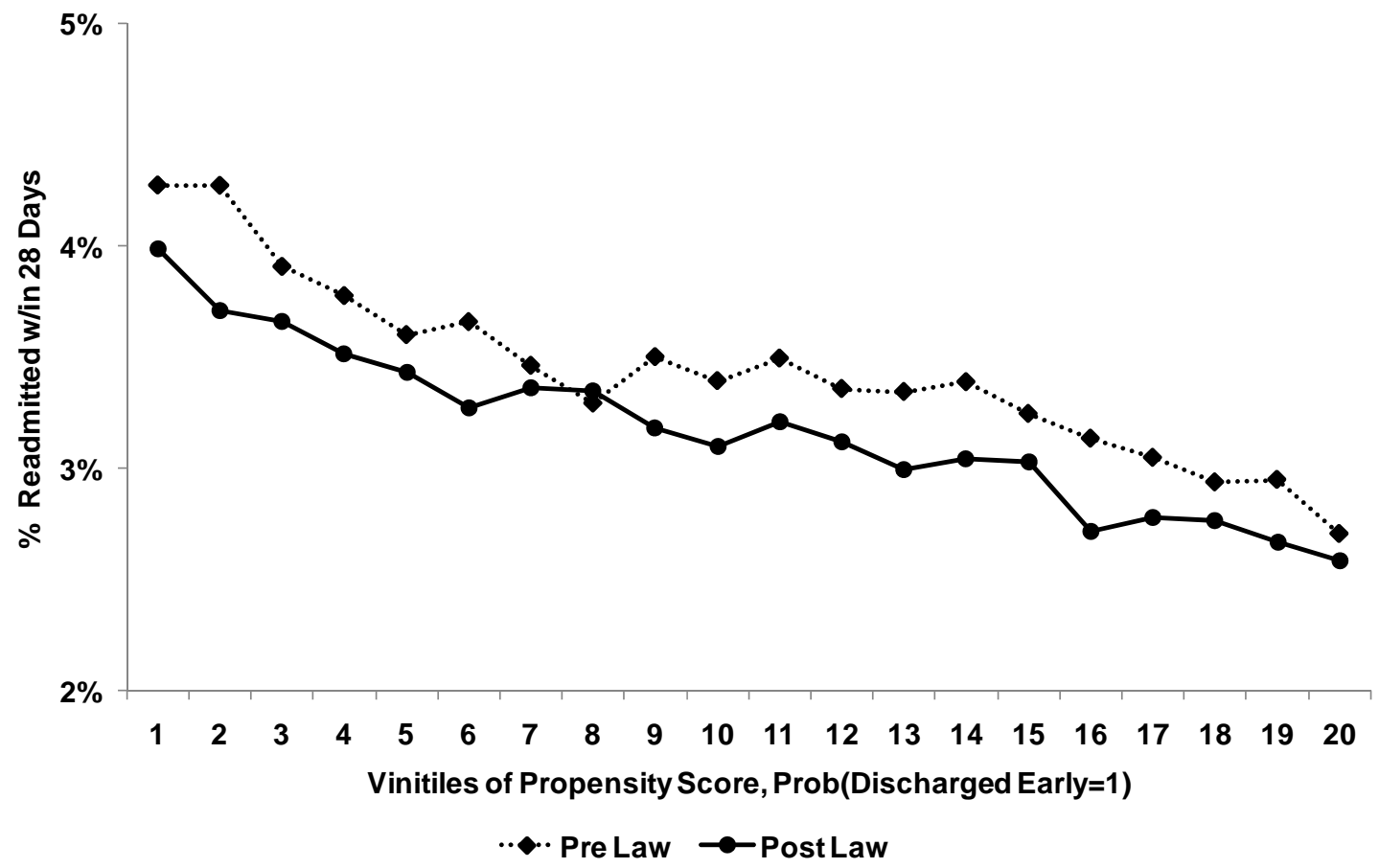


Table 1

Sample Means, Privately Insured and Medicaid Births in California, 1995-2000

\begin{tabular}{|c|c|c|}
\hline Variable & $\begin{array}{c}\text { Pre law period } \\
\text { Jan 1995-Aug } 1997\end{array}$ & $\begin{array}{c}\text { Post law period } \\
\text { Jan 1998-Dec } 2000\end{array}$ \\
\hline Discharged early $(1=$ yes, $0=$ no $)$ & 0.788 & 0.511 \\
\hline 28 day readmission $(1=$ yes, $0=$ no $)$ & 0.034 & 0.032 \\
\hline Medicaid birth $(1=$ yes, $0=$ no $)$ & 0.48 & 0.418 \\
\hline C-section $(1=$ yes, $0=$ no $)$ & 0.207 & 0.225 \\
\hline Birth weight (in ounces) & 119.53 & 119.6 \\
\hline Gestation (in days) & 276.84 & 276.25 \\
\hline \multicolumn{3}{|l|}{ No pregnancy/deliver problems } \\
\hline$(1=$ yes, $0=$ no $)$ & 0.798 & 0.797 \\
\hline \multicolumn{3}{|l|}{ Mother's education $(1=$ yes, $0=$ no $)$} \\
\hline$<$ High school & 0.331 & 0.296 \\
\hline High school graduate & 0.479 & 0.480 \\
\hline College graduate & 0.180 & 0.211 \\
\hline \multicolumn{3}{|l|}{ Mother's race $(1=$ yes, $0=$ no $)$} \\
\hline White & 0.813 & 0.803 \\
\hline Black & 0.070 & 0.065 \\
\hline Other & 0.118 & 0.132 \\
\hline \multicolumn{3}{|l|}{ Mother's Age $(1=$ yes, $0=$ no $)$} \\
\hline$<20$ & 0.163 & 0.149 \\
\hline$\geq 20,<25$ & 0.244 & 0.234 \\
\hline$\geq 25,<30$ & 0.271 & 0.272 \\
\hline$\geq 30,<35$ & 0.215 & 0.222 \\
\hline$\geq 35,<40$ & 0.091 & 0.103 \\
\hline$\geq 40$ & 0.015 & 0.018 \\
\hline Mother is Hispanic ( $1=$ yes, $0=$ no $)$ & 0.431 & 0.441 \\
\hline Observations & $1,176,797$ & $1,322,859$ \\
\hline
\end{tabular}

Numbers in parentheses are standard deviations. 
Table 2: OLS and 2SLS Estimates of 28-Day readmission Equation, Privately Insured and Medicaid Births in California, January 1995-August 1996, January 199-December

\begin{tabular}{|c|c|}
\hline \multicolumn{2}{|c|}{ OLS Estimates of 28-day readmission equation in pre-law period } \\
\hline \multirow[t]{2}{*}{ Discharged early } & 0.001 \\
\hline & $(0.0007)$ \\
\hline $\mathrm{R}^{2}$ & 0.0036 \\
\hline \multicolumn{2}{|l|}{ Sample means, prelaw period } \\
\hline Early Discharge & 0.034 \\
\hline 28-day readmissions & 0.788 \\
\hline Observations & $1,176,797$ \\
\hline \multicolumn{2}{|l|}{$1^{\text {st }}$ stage estimates, Discharged Early equation } \\
\hline \multirow{2}{*}{$\begin{array}{l}\text { Private ins. } \mathrm{x} \text { vaginal delivery } \mathrm{x} \\
\text { Federal law }\end{array}$} & $-0.296 * * *$ \\
\hline & $(0.002)$ \\
\hline \multirow{2}{*}{ Private ins. $\mathrm{x}$ c-section $\mathrm{x}$} & $-0.137 * * *$ \\
\hline & $(0.003)$ \\
\hline \multirow{2}{*}{$\begin{array}{l}\text { Medicaid x vaginal delivery } \mathrm{x} \\
\text { Federal law }\end{array}$} & $-0.137 * * *$ \\
\hline & $(0.002)$ \\
\hline Medicaid x c-section $\mathrm{x}$ & $-0.031 * * *$ \\
\hline Federal law & $(0.004)$ \\
\hline \multirow{2}{*}{$\begin{array}{l}\text { Medicaid } \mathrm{x} \text { vaginal delivery } \mathrm{x} \\
\text { state expansion }\end{array}$} & $-0.067 * * *$ \\
\hline & $(0.002)$ \\
\hline \multirow{2}{*}{$\begin{array}{l}\text { Medicaid x c-section } \mathrm{x} \\
\text { state expansion }\end{array}$} & $-0.052 * * *$ \\
\hline & $(0.003)$ \\
\hline F-test, $\mathrm{H}_{\mathrm{o}}$ : all instruments $=0$ & 5923.2 \\
\hline (p-value) & $(0.000)$ \\
\hline Observations & $2,499,656$ \\
\hline \multicolumn{2}{|l|}{ 2SLS Estimates, 28-day readmission equation } \\
\hline \multirow[t]{2}{*}{ Discharged early } & 0.005 \\
\hline & $(0.003)$ \\
\hline \multirow{2}{*}{$\begin{array}{l}\text { P-value, test of over-identifying } \\
\text { restrictions }\end{array}$} & 0.0574 \\
\hline & \\
\hline Obsevations & $2,499,656$ \\
\hline
\end{tabular}

Standard errors (in parenthesis) were calculated allowing for an arbitrary correlation in errors within hospitals over time. Other covariates in the model include cubic terms in birth weight and gestation, fixed effects for mother's age, race, ethnicity, education, previous births, multiple births, the month, weekday and hour of the day, the size, location and ownership status of the hospital, and the baby's sex. The models also include dummies for the interaction of delivery type (c-section versus vaginal) and insurance status (private versus Medicaid), plus a unique monthly time trend for each of these unique combinations. $*=$ p-value $<0.10$

$* *=$ p-value $<0.05$

$* * *=$ p-value $<0.001$ 
Table 3: OLS and 2SLS Estimates of 28-Day readmission Equation, Privately Insured and Medicaid Births in California, January 1995-August 1996, January 199-December

\begin{tabular}{|c|c|c|c|c|c|c|c|c|}
\hline \multirow[b]{2}{*}{ Sample } & \multirow[b]{2}{*}{ Obs. } & \multicolumn{2}{|c|}{ Means in pre-law period } & \multicolumn{2}{|c|}{$\begin{array}{l}\text { Coefficient (standard error) on } \\
\text { Discharged Early Variable }\end{array}$} & \multirow[b]{2}{*}{$\begin{array}{l}\text { P-value test } \\
\text { of overid. }\end{array}$} & \multirow[b]{2}{*}{$\begin{array}{c}\text { No. } \\
\text { instruments }\end{array}$} & \multirow{2}{*}{$\begin{array}{c}\text { F-test } \\
\text { (P-value) } \\
\text { First stage } \\
\text { instruments }\end{array}$} \\
\hline & & $\begin{array}{l}\text { Discharged } \\
\text { Early }\end{array}$ & $\begin{array}{l}28 \text {-day } \\
\text { readmission }\end{array}$ & OLS & 2SLS & & & \\
\hline Full Sample & $2,499,656$ & 0.788 & 0.034 & $\begin{array}{c}0.001 \\
(0.0007)\end{array}$ & $\begin{array}{l}0.0047^{*} \\
(0.0028)\end{array}$ & 0.0574 & 6 & $\begin{array}{l}5,923.2 \\
(0.000)\end{array}$ \\
\hline C-sections & 541,042 & 0.863 & 0.028 & $\begin{array}{r}0.003 * * \\
(0.001)\end{array}$ & $\begin{array}{l}0.019 * * \\
(0.009)\end{array}$ & 0.1397 & 3 & $\begin{array}{c}782.3 \\
(0.000)\end{array}$ \\
\hline Vaginal deliveries & $1,958,614$ & 0.768 & 0.036 & $\begin{array}{c}0.0007 \\
(0.0008)\end{array}$ & $\begin{array}{c}0.004 \\
(0.003)\end{array}$ & 0.0691 & 3 & $\begin{array}{l}10,832.7 \\
(0.00)\end{array}$ \\
\hline No problems & $1,992,783$ & 0.815 & 0.034 & $\begin{array}{l}-0.0007 \\
(0.0008)\end{array}$ & $\begin{array}{c}0.0024 \\
(0.0029)\end{array}$ & 0.2254 & 6 & $\begin{array}{l}5,087.2 \\
(0.000)\end{array}$ \\
\hline $1+$ problems & 506,873 & 0.68 & 0.038 & $\begin{array}{l}0.006^{* * *} * \\
(0.0013)\end{array}$ & $\begin{array}{l}0.016^{* *} \\
(0.0067)\end{array}$ & 0.4542 & 6 & $\begin{array}{l}893.4 \\
(0.000)\end{array}$ \\
\hline $2+$ problems & 115,441 & 0.552 & 0.042 & $\begin{array}{c}0.014 * * * \\
(0.002)\end{array}$ & $\begin{array}{l}0.032 * \\
(0.017)\end{array}$ & 0.5300 & 6 & $\begin{array}{l}132.7 \\
(0.000)\end{array}$ \\
\hline $3+$ problems & 27,102 & 0.43 & 0.041 & $\begin{array}{c}0.021 \\
(0.005)\end{array}$ & $\begin{array}{c}0.050 \\
(0.035) \\
\end{array}$ & 0.1480 & 6 & $\begin{array}{c}22.0 \\
(0.000)\end{array}$ \\
\hline
\end{tabular}

Standard errors (in parenthesis) were calculated allowing for an arbitrary correlation in errors within hospitals over time. Other covariates in the model include cubic terms in birth weight and gestation, fixed effects for mother's age, race, ethnicity, education, previous births, multiple births, the month, weekday and hour of the day, the size, location and ownership status of the hospital, and the baby's sex. The models also include dummies for the interaction of delivery type (c-section versus vaginal) and insurance status (private versus Medicaid), plus a unique monthly trend for each of these unique combinations.

$*=$-value $<0.10$

$* *=\mathrm{p}$-value $<0.05$

$* * *=$ p-value $<0.001$ 
Table 4: OLS and 2SLS Estimates of 28-Day readmission Equation, Privately Insured and Medicaid Births in California,

\begin{tabular}{|c|c|c|c|c|c|c|c|c|}
\hline \multirow[b]{2}{*}{ Sample } & \multirow[b]{2}{*}{ Obs. } & \multicolumn{2}{|c|}{ Means in pre-law period } & \multicolumn{2}{|c|}{$\begin{array}{l}\text { Coefficient (standard } \\
\text { error) on Discharged } \\
\text { Early Variable }\end{array}$} & \multirow{2}{*}{$\begin{array}{l}\text { P-value } \\
\text { test of } \\
\text { overid. }\end{array}$} & \multirow{2}{*}{$\begin{array}{c}\text { No. } \\
\text { instruments }\end{array}$} & \multirow{2}{*}{$\begin{array}{c}\text { F-test } \\
\text { (P-value) } \\
\text { First stage } \\
\text { instruments }\end{array}$} \\
\hline & & Early & readmission & OLS & 2SLS & & & \\
\hline Full sample & $2,499,656$ & 0.788 & 0.034 & $\begin{array}{c}0.001 \\
(0.0007) \\
\end{array}$ & $\begin{array}{l}0.0047^{*} \\
(0.0028) \\
\end{array}$ & 0.0574 & 6 & $\begin{array}{l}5,923.2 \\
(0.000) \\
\end{array}$ \\
\hline \multicolumn{9}{|c|}{ By Specific Complications and Conditions } \\
\hline Meconium delivery & 114,416 & 0.739 & 0.032 & $\begin{array}{c}-0.004 * * \\
(0.002)\end{array}$ & $\begin{array}{c}0.019 \\
(0.014)\end{array}$ & 0.2561 & 6 & $\begin{array}{l}245.2 \\
(0.000)\end{array}$ \\
\hline Fetal distress & 70,005 & 0.718 & 0.034 & $\begin{array}{l}0.006^{*} \\
(0.003)\end{array}$ & $\begin{array}{c}0.044 * * \\
(0.021)\end{array}$ & 0.0571 & 6 & $\begin{array}{c}96.1 \\
(0.000)\end{array}$ \\
\hline Preclampsia/eclampsia & 54,042 & 0.605 & 0.040 & $\begin{array}{c}0.008 * * \\
(0.003)\end{array}$ & $\begin{array}{c}0.0543^{* *} \\
(0.022)\end{array}$ & 0.7422 & 6 & $\begin{array}{c}77.4 \\
(0.000)\end{array}$ \\
\hline Diabetes & 51,848 & 0.72 & 0.042 & $\begin{array}{c}0.007^{* *} \\
(0.003)\end{array}$ & $\begin{array}{l}0.035^{*} \\
(0.021)\end{array}$ & 0.8741 & 6 & $\begin{array}{l}102.0 \\
(0.000)\end{array}$ \\
\hline $\begin{array}{l}\text { Other dysfunctional } \\
\text { delivery }\end{array}$ & 44,722 & 0.83 & 0.032 & $\begin{array}{l}-0.003 \\
(0.004)\end{array}$ & $\begin{array}{c}0.0143 \\
(0.0263)\end{array}$ & 0.269 & 6 & $\begin{array}{c}54.0 \\
(0.000)\end{array}$ \\
\hline \multicolumn{9}{|c|}{ By Birthweight } \\
\hline Birthweight $<5$ lbs & 36,964 & 0.288 & 0.042 & $\begin{array}{c}0.027 * * * \\
(0.005)\end{array}$ & $\begin{array}{c}0.053 \\
(0.047)\end{array}$ & 0.5525 & 6 & $\begin{array}{c}20.2 \\
(0.000)\end{array}$ \\
\hline Birthweight $\geq 5$ lbs & $2,462,692$ & 0.795 & 0.034 & $\begin{array}{c}0.0004 \\
(0.0005) \\
\end{array}$ & $\begin{array}{c}0.005 \\
(0.003) \\
\end{array}$ & 0.0793 & 6 & $\begin{array}{r}5926.9 \\
(0.000) \\
\end{array}$ \\
\hline
\end{tabular}

Standard errors (in parenthesis) were calculated allowing for an arbitrary correlation in errors within hospitals over time. Other covariates in the model include cubic terms in birth weight and gestation, fixed effects for mother's age, race, ethnicity, education, previous births, multiple births, the month, weekday and hour of the day, the size, location and ownership status of the hospital, and the baby's sex. The models also include dummies for the interaction of delivery type (c-section versus vaginal) and insurance status (private versus Medicaid), plus a unique monthly trend for each of these unique combinations.

$*=$-value $<0.10$

$* *=$-value $<0.05$

$* * *=$ p-value $<0.001$ 
Table 5: OLS and 2SLS Estimates of 28-Day readmission Equation, Privately Insured and Medicaid Births in California,

January 1995-August 1996, January 199-December

\begin{tabular}{|c|c|c|c|c|c|c|c|c|}
\hline \multirow[b]{2}{*}{ Sample } & \multirow[b]{2}{*}{ Obs. } & \multicolumn{2}{|c|}{$\begin{array}{c}\text { Means in pre-treatment } \\
\text { period }\end{array}$} & \multicolumn{2}{|c|}{$\begin{array}{l}\text { Coefficient (standard } \\
\text { error) on Discharged } \\
\text { Early Variable }\end{array}$} & \multirow{2}{*}{$\begin{array}{c}\text { P-value } \\
\text { test of } \\
\text { overid. }\end{array}$} & \multirow[b]{2}{*}{$\begin{array}{c}\text { No. } \\
\text { instruments }\end{array}$} & \multirow{2}{*}{$\begin{array}{c}\text { F-test } \\
(\mathrm{P} \text {-value }) \\
\text { First stage } \\
\text { instruments }\end{array}$} \\
\hline & & $\begin{array}{l}\text { Discharged } \\
\text { Early }\end{array}$ & $\begin{array}{l}28 \text {-day } \\
\text { readmission }\end{array}$ & OLS & 2SLS & & & \\
\hline \multicolumn{9}{|l|}{ Full sample } \\
\hline \multicolumn{9}{|c|}{ By halves of the propensity score of Discharged early } \\
\hline Bottom half & $1,249,829$ & 0.674 & 0.037 & $\begin{array}{l}0.002 * * \\
(0.0009)\end{array}$ & $\begin{array}{l}0.007^{*} \\
(0.004)\end{array}$ & 0.0650 & 6 & $\begin{array}{l}3,116.6 \\
(0.000)\end{array}$ \\
\hline Top half & $1,249,827$ & 0.905 & 0.032 & $\begin{array}{l}-0.002^{*} \\
(0.001)\end{array}$ & $\begin{array}{l}0.003 \\
(0.003)\end{array}$ & 0.6699 & 6 & $\begin{array}{l}2,968.5 \\
(0.000)\end{array}$ \\
\hline \multicolumn{9}{|c|}{ By thirds of the propensity score of Discharged Early } \\
\hline Bottom third & 833,219 & 0.599 & 0.039 & $\begin{array}{c}0.003 * * \\
(0.001)\end{array}$ & $\begin{array}{l}0.011 * * \\
(0.005)\end{array}$ & 0.3006 & 6 & $\begin{array}{l}1,679.8 \\
(0.000)\end{array}$ \\
\hline Middle third & 833,219 & 0.853 & 0.034 & $\begin{array}{l}-0.0004 \\
(0.001)\end{array}$ & $\begin{array}{c}0.001 \\
(0.003)\end{array}$ & 0.2620 & 6 & $\begin{array}{r}2,986.7 \\
(0.000\end{array}$ \\
\hline Top third & 833,218 & 0.920 & 0.030 & $\begin{array}{l}-0.002^{*} \\
(0.001)\end{array}$ & $\begin{array}{c}0.005 \\
(0.005)\end{array}$ & 0.1526 & 6 & $\begin{array}{l}1,495.2 \\
(0.000)\end{array}$ \\
\hline
\end{tabular}

Standard errors (in parenthesis) were calculated allowing for an arbitrary correlation in errors within hospitals over time. Other covariates in the model include cubic terms in birth weight and gestation, fixed effects for mother's age, race, ethnicity, education, previous births, multiple births, the month, weekday and hour of the day, the size, location and ownership status of the hospital, and the baby's sex. The models also include dummies for the interaction of delivery type (c-section versus vaginal) and insurance status (private versus Medicaid), plus a unique monthly trend for each of these unique combinations.

$*=$-value $<0.10$

$* *=$-value $<0.05$

$* * *=p$-value $<0.001$ 